\title{
Recent Advances on Asymmetric Nitroso Aldol Reaction
}

Pedro Merino, ${ }^{* a}$ Tomás Tejero, ${ }^{a}$ Ignacio Delso ${ }^{\mathrm{a}, \mathrm{b}}$ and Rosa Matute ${ }^{\mathrm{c}}$

${ }^{a}$ Laboratorio de Síntesis Asimétrica. Departamento de Síntesis y Estructura de Biomoléculas. Instituto de Síntesis Química y Catálisis Homogénea (ISQCH). Universidad de Zaragoza. CSIC. Campus San Francisco. 50009 Zaragoza, Aragón, Spain.

${ }^{b}$ Servicio de Resonancia Magnética Nuclear. CEQMA. Universidad de Zaragoza. CSIC. Campus San Francisco. 50009 Zaragoza, Aragón, Spain.

${ }^{c}$ Departamento de Ingeniería Química y Tecnologías del Medio Ambiente. Escuela Universitaria de Ingeniería Industrial. Edificio Torres Quevedo. Campus Actur. 50014 Zaragoza, Aragón, Spain;

Phone: +34 876 553783.E-mail:pmerino@unizar.es

\section{Graphical Abstract}

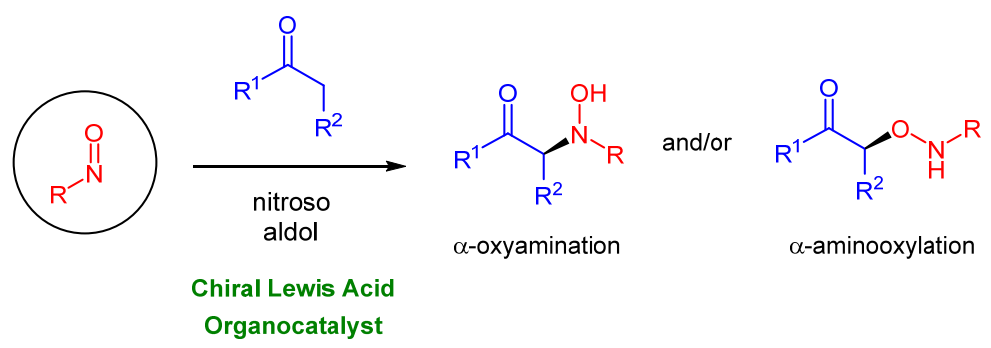

\section{Biographical Sketch}

\begin{abstract}
The reaction of aromatic nitroso derivatives with enolizable carbonyl compounds (nitroso aldol reaction) to give either $\alpha$-hydroxyamino or $\alpha$-aminoxycarbonyls is an important synthetic method. This review illustrates the recent advances in rendering the process regio- and enantioselective as well as catalytic. By employing metal and organic catalysts one can generate a range of $\alpha$-amino ( $\alpha$-oxyamination) and $\alpha$-hydroxy ( $\alpha$ aminoxylation) carbonyl derivatives with total regioselectivity and high levels of enantiomeric excess.
\end{abstract}




\section{Introduction}

The introduction of amino and oxygen functionalities in an organic molecule is among the most important tools employed in synthetic chemistry, particularly if it is achieved in an enantioselective way. Chiral molecules bearing amino and/or hydroxy groups are ubiquitous in natural products and therapeutic drugs; also, they are of a great utility as synthetic intermediates. Of particular interest are those derivatives in which the heteroatom is in proximity to other reactive functional group, like a carbonyl, that allow for further chemical elaboration. In this context, organic nitroso compounds $\mathbf{1}$ are valuable intermediates because of the particular reactivity of the nitroso group ${ }^{1,2}$ that allow multiple reactivity as $N$ - and $O$-electrophiles in amination and hydroxylation reactions, respectively (nitroso aldol) ${ }^{3}$ as well as enophiles in cycloaddition reactions (Scheme 1). ${ }^{4}$ Both the nitroso ene $\mathrm{e}^{5-7}$ and nitroso Diels-Alder ${ }^{8-11}$ reactions have been studied widely.

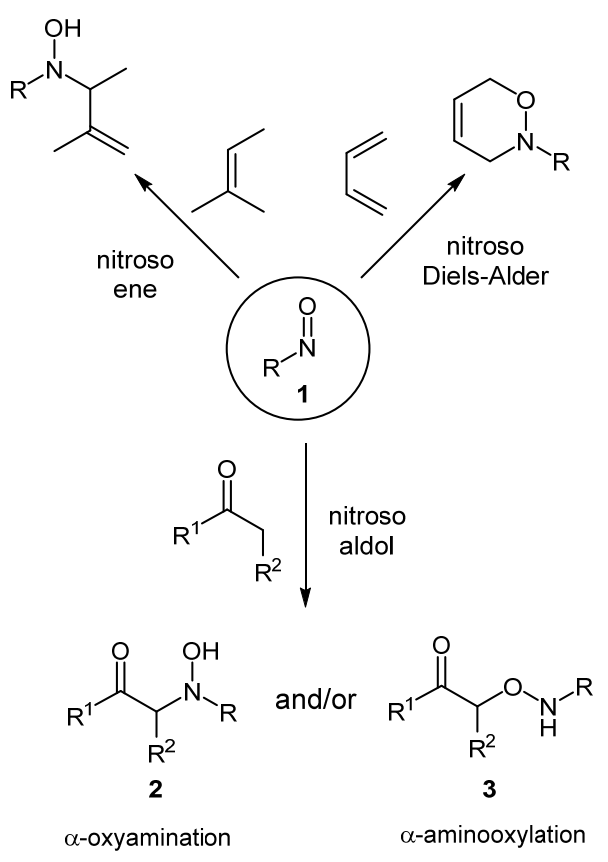

Scheme 1. Main reactivity of nitroso compounds

The main problem of the nitroso aldol reaction is the regioselectivity. If the addition takes place on the nitrogen atom of the nitroso group, $\alpha$-amino carbonyls $\mathbf{2}$ are obtained, through an $\alpha$-oxyamination process. On the other hand, when the addition take place on the oxygen atom of the nitroso group, $\alpha$-hydroxy carbonyls $\mathbf{3}$ are obtained through a typical $\alpha$-aminoxylation reaction. In some instances, the term "nitroso aldol reaction" only refers to the $\alpha$-oxyamination process by analogy between $\mathrm{N}=\mathrm{O}$ and $\mathrm{C}=\mathrm{O}$ funtionalities whereas the term " $\alpha$-aminoxylation" is preferred for the $O$-selective 
reactions. Since both processes correspond to the reaction between a carbonyl group and a nitroso compound we will consider both of them in this revision. In general, the regioselectivity of the reaction can be controlled by the action (or absence) of a Lewis acid. Whereas the reaction proceeds through $\mathrm{N}$-addition with in situ generated or preformed enolates (usually, lithium, tin or silicon), ${ }^{12} \mathrm{O}$-addition is observed if the reaction is catalyzed by a Lewis acid (Scheme 2). ${ }^{13}$ In addition to trimethylsilyl triflate, various metal ions including copper, cobalt, iron, silver, gold and hafnium promote an $O$-selective nitroso aldol reaction. ${ }^{14}$ It has been suggested ${ }^{15}$ that in the Lewis acid promoted reaction, the aminooxy compounds could come from a nitroso dimer generated in situ in the presence of the Lewis acid. Simple enolates would give rise to hydroxyamino compounds through the nitroso monomer.

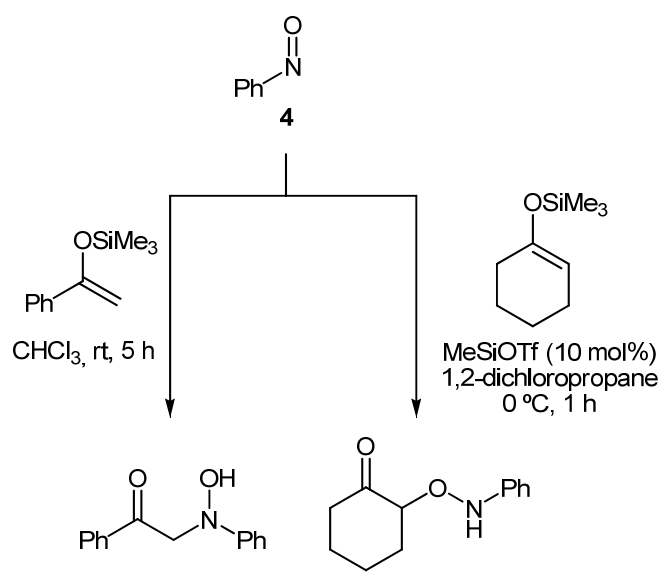

Scheme 2. Regioselective nitroso aldol reactions

In the last years, remarkable advances have been made in the use of nitroso compounds for preparing $\alpha$-amino and $\alpha$-hydroxy carbonyl compounds in an enantioselective way through asymmetric $\alpha$-aminoxylation ${ }^{16}$ and $\alpha$-oxyamination ${ }^{17}$ reactions, respectively. Some aspects of nitroso aldol reaction have been included as a part of more general reviews, ${ }^{1,3,4}$ including those dedicated to the highly reactive nitrosocarbonyl compounds. ${ }^{18}$ This review aims to provide coverage -from the last 15 years- of recent advances in nitroso aldol reactions mainly considering both metal-catalyzed and organocatalyzed processes. In addition to nitroso aldol reactions with aldehydes and ketones, we review reactions of related enamines with nitroso compounds. The review has been categorized by the type of catalysis. For the sake of clarity, differences in regioselectivity have been discussed when necessary for each particular case.

\section{Metal-Catalyzed Reactions}


A general asymmetric $O$-selective nitroso aldol reaction was developed using tin enolates derived from ketones and nitrobenzene. Optimization studies led to the identification of catalysts that produce excellent regio- and enantioselectivities for a range of alkyl and aryl-substituted tin enolates. The catalysts consisted of BINAP-silver complexes formed by combining $(R)$-BINAP and $(R)$-TolBINAP with silver salts such as $\mathrm{AgOTf}$ and $\mathrm{AgClO}_{4}$ (Table 1). ${ }^{19}$ The reaction was independent of any variation in cyclic tin enolate, although tributyl tin enolates had slightly increased $N$-selectivity. Taking into account that $N$-selective nitroso aldol reactions occur in the absence of catalyst, a competitive experiment between tributyl and trimethyl tin enolates demonstrated that the higher reactivity of tributyltin enolates resulted in more significant uncatalyzed process.

Table 1 O-Nitroso Aldol Reaction of Tin Enolates ${ }^{a}$

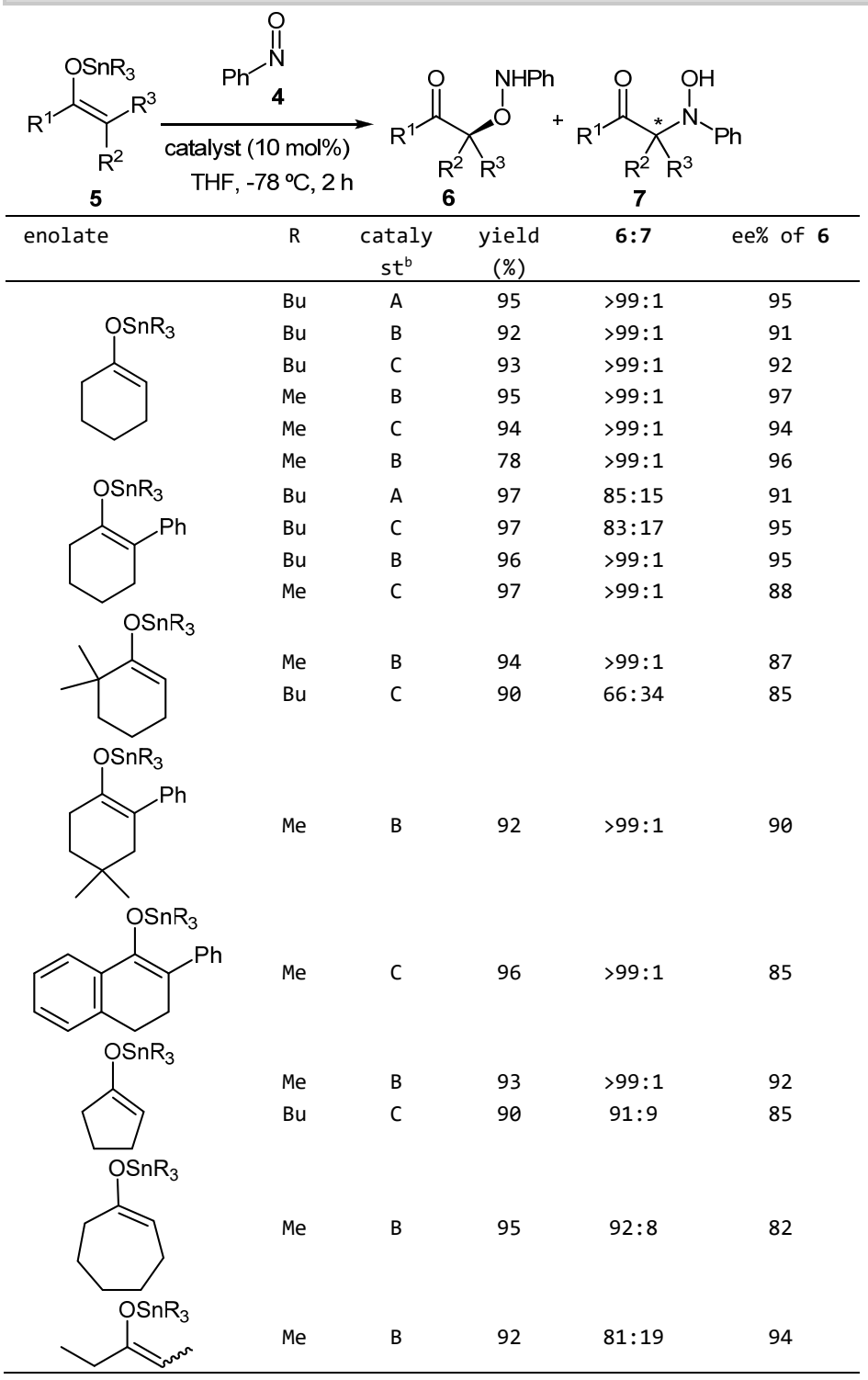


a Reactions were conducted with 1.0 equiv of nitrosobenzene and 1.0 equiv of tin enolate. ${ }^{b}$ Catalyst $A$ : (R)-

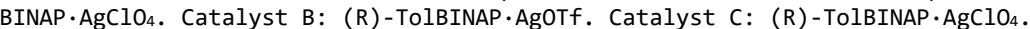

The reaction was extended, with excellent results, to less toxic disilanyl enol ethers $\mathbf{8}$ by using silver tetrafluoroborate as silver source and 3,3'-diphenyl (S)-binol-derived phosphite 9 as a ligand (Scheme 3). ${ }^{20}$ The reaction required an excess of cesium fluoride to proceed.

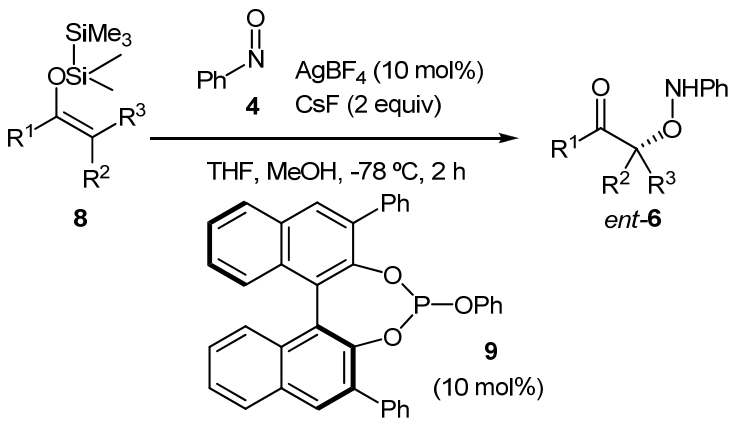<smiles>O=C1CCCC[C@H]1ONc1ccccc1</smiles>

$(85 \%, 95 \%$ ee)<smiles>O=C1CCC[C@@H]1ONc1ccccc1</smiles>

$(41 \%, 90 \%$ ee $)$<smiles>CC1(C)CCC(=O)[C@H](ONc2ccccc2)C1</smiles>

(72\%, 98\% ee)<smiles>O=C1CCOC[C@H]1ONc1ccccc1</smiles>

(6\%, $97 \%$ ee)<smiles>O=C1CCCCC[C@H]1ONc1ccccc1</smiles>

(37\%, 64\% ee)<smiles>O=C1CCC2(CCCC2)C[C@H]1ONc1ccccc1</smiles>

(85\%, 96\% ee)<smiles>O=C1c2ccccc2CC[C@@H]1ONc1ccccc1</smiles>

(84\%, 92\% ee)<smiles>O=C1CCCC[C@]1(ONc1ccccc1)c1ccccc1</smiles>

(85\%, 95\% ee)<smiles>O=C1CCCC[C@@]1(I)ONc1ccccc1</smiles>

(85\%, 95\% ee)

\section{Scheme 3}

$\alpha$-Aminooxy ketones were prepared with enantioselectivities of up to $99 \%$ from alkenyl trichloroacetates 10 by using $t-\mathrm{Bu}-\mathrm{QuinoxP*} 11$ in complex with AgOAc as the chiral catalyst and dibutyl(methoxy)- $\lambda^{3}$-stannane as the achiral cocatalyst (Table 2$) .{ }^{21}$ The reaction, which is not completely $O$-selective, seems to proceed through a tin enolate formed in situ which adds enantioselectively to nitrosobenzene in the presence of the chiral catalyst. The driving force of the catalytic cycle originates from the rapid methanolysis of an intermediate tin amide. 


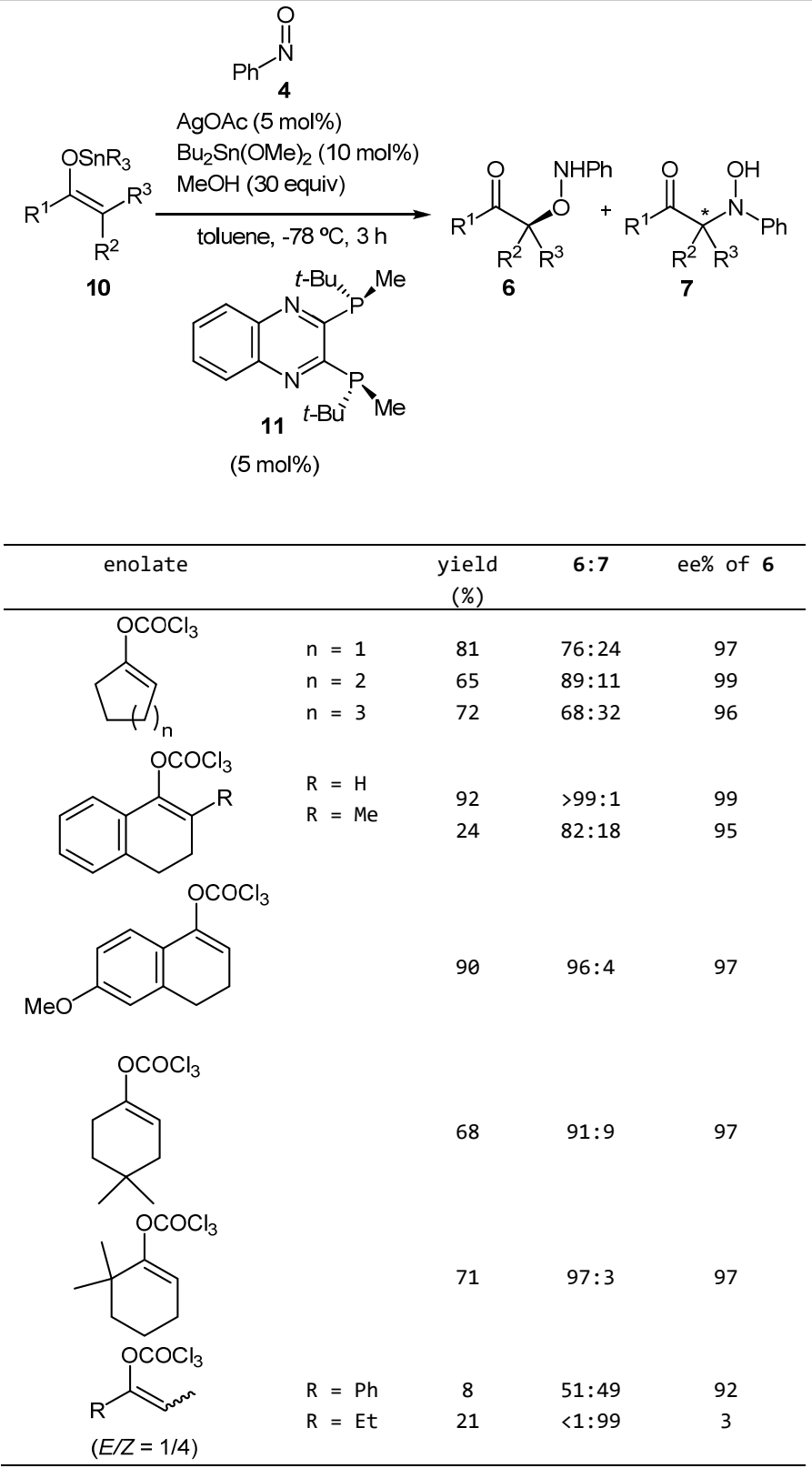

a Reactions were conducted with 1.0 equiv of nitrosobenzene and 2.0 equiv of alkenyl trichloroacetate.

The first example of $\mathrm{Cu}$-catalyzed $\mathrm{O}$-nitroso aldol reaction has been reported by Yamamoto and co-workers. ${ }^{22}$ The methodology was applied to $\beta$-keto(thio)esters 12 and highly enantioenriched $\alpha$-aminooxy- $\beta$-ketoesters 15 were prepared (Scheme 4 ). The nitroso derivative was generated in situ from the commercially available $N$-Boc hydroxylamine $\mathbf{1 3}$ and manganese(IV) as an oxidant. The reaction was conducted in the presence of copper(II) triflate and bisoxazoline $(R, R)-\mathrm{PhBox} 14$ as ligand. The slow addition of $N$-Boc-hydroxylamine was crucial to avoid condensation between the in situ formed nitrosocarbonyl species and excess 13. The reaction showed a high preference for $O$-selectivity and only traces of $N$-nitroso carbonyl aldol were detected. 


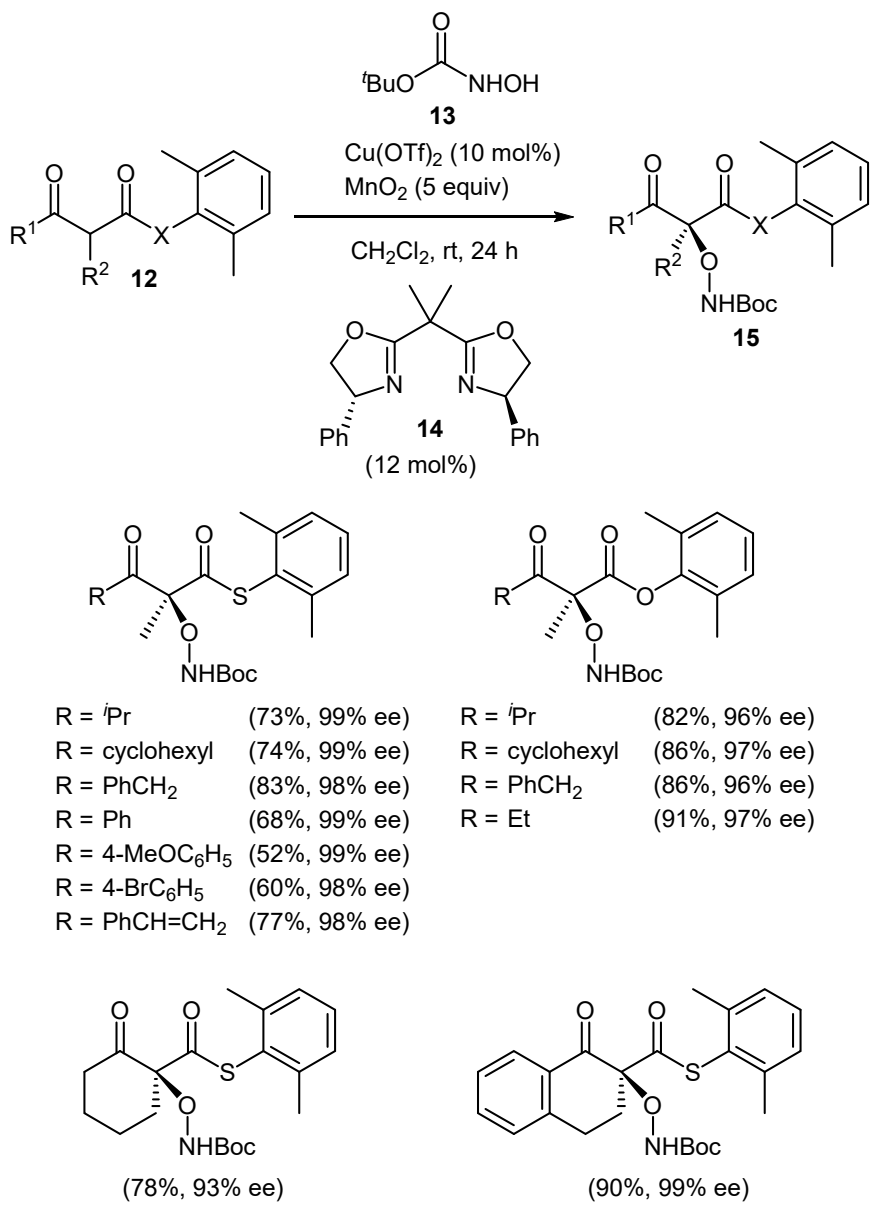

\section{Scheme 4}

The reaction has also been carried out by generating the nitroso derivative under aerobic oxidation conditions from the corresponding $N$-(benzyloxycarbonyl) hydroxylamine 17. The procedure involved mixing of all reagents at room temperature and illustrated a fully catalytic process in both oxidation and enolization processes. ${ }^{23}$ A combination of copper(I) chloride and copper(II) acetate was used as Lewis acid; chirality was induced by using ligand 14 (Scheme 5). Notably, when copper(II) acetate was replaced by copper(II) triflate and no chiral ligand was added the reaction was $N$-selective providing, obviously, racemic substrates. ${ }^{24}$

The choice of the ester was crucial for achieving good values of enantioselectivity, the more sterically demanding groups (e.g. tert-butyl and 2,6-xylyl) giving rise to the best values. 


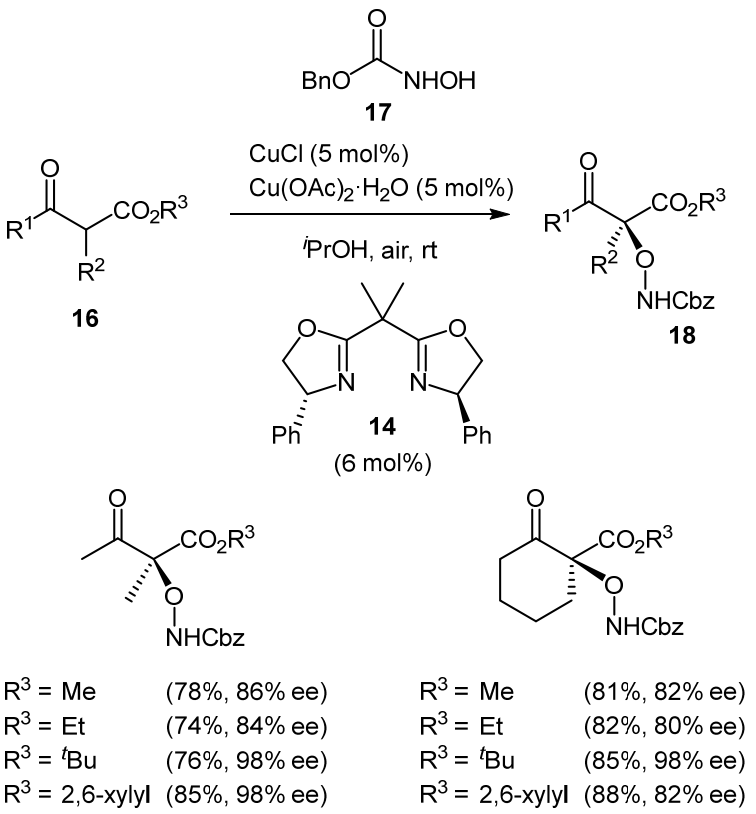

\section{Scheme 5}

A model of addition has been suggested based on the experimental observations (Figure 1). Read de Alaniz and co-workers proposed ${ }^{23}$ the approach of the nitrosocarbonyl to the catalyst-coordinated $\beta$-ketoester by the same face in which the counterion occupies an axial position, thus preventing both coordination of the nitroso species to the Lewis acid and unfavourable steric interactions between the protecting group of the nitroso species and the complex. In agreement with this proposal is the observation that bulkier protecting groups, such as Boc, provided better enantioselectivities. ${ }^{22}$

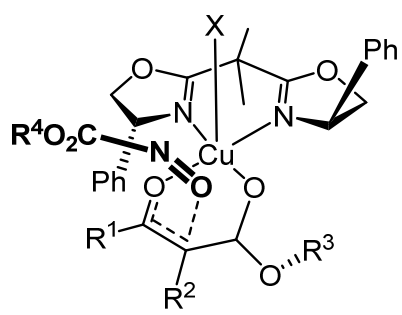

Figure 1. Model of addition for $\mathrm{Cu}$-catalyzed nitroso aldol reaction $(\mathrm{X}=$ counterion $)$

Application of the methodology illustrated in Scheme 4 allowed preparation of substituted $\alpha$-aminooxyphosphonates 20 of synthetic utility when $\beta$-ketophosphonates 19 were employed as starting materials. An example is illustrated in Scheme 6 showing the possibility of obtaining $\alpha$-hydroxyphosphonates $21, \alpha, \beta$-dihydroxyphosphonates 22 and $\beta$-amino- $\alpha$-hydroxyphosphonates $23 .{ }^{25}$ The reaction proceeded in very good yields and enantioselectivities with both acyclic and cyclic substrates at the ketone moiety. On 
the other hand, compounds bearing an ester (Scheme 6, $\mathrm{R}=\mathrm{OMe}$ ) or thioester (Scheme $5, \mathrm{R}=\mathrm{SPh}$ ) in place of the ketone group gave no reaction.

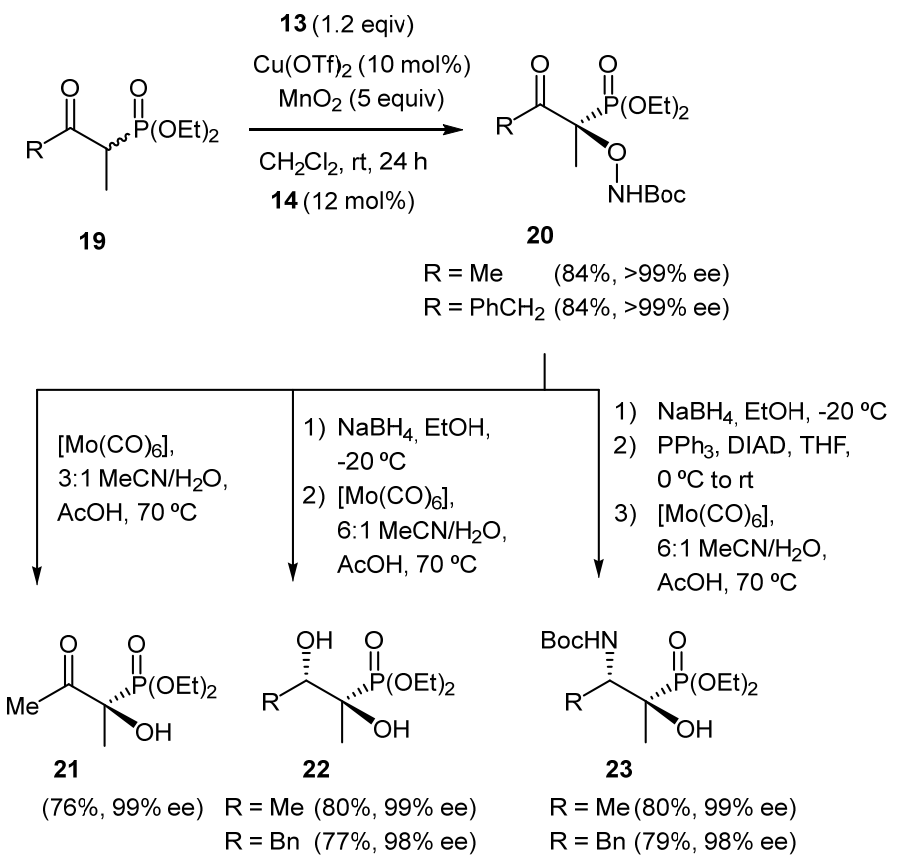

\section{Scheme 6}

The vinylogous nitroso Mukaiyama aldol reaction has been reported by using silyl enolates derived from $\alpha, \beta$-unsaturated esters as starting materials and acetic acid or HF.Py as promoters. ${ }^{26}$ Nitrosobenzene was added in an excess thus promoting the N-O cleavage of the in situ generated $\gamma$-aminoxy species. Under such conditions racemic $\gamma$ hydroxy $\alpha, \beta$-unsaturated esters were obtained. When the reaction was conducted with silyl enolate $\mathbf{2 4}$ derived from (-)-carvone, enantiomerically pure (+)-5 $\alpha$-hydroxycarvone 25 was obtained (Scheme 7).
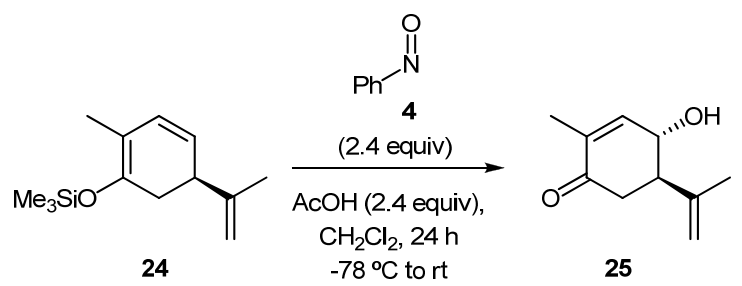

25

\section{Scheme 7}

The first example of a catalytic enantioselective $N$-nitroso aldol reaction was reported using BINAP-silver complexes ${ }^{27}$ which were developed based on previously reported asymmetric catalysts that promote $O$-selective reactions. ${ }^{19}$ In particular, for the reaction between tin enolates and nitrosobenzene, whereas AgOTf, $\mathrm{AgOAc}$ and $\mathrm{AgOCOCF}_{3}-$ derived 1:1 complexes with $(R)$-BINAP were shown to be efficient catalysts in $O$ selective nitroso aldol reactions (see above), the reaction catalyzed by the $2: 1$ complex 
26, generated from 0.4 equiv of $(R)$-BINAP for AgOTf, resulted completely $N$-selective affording high enantioselectivites (Table 3 ).

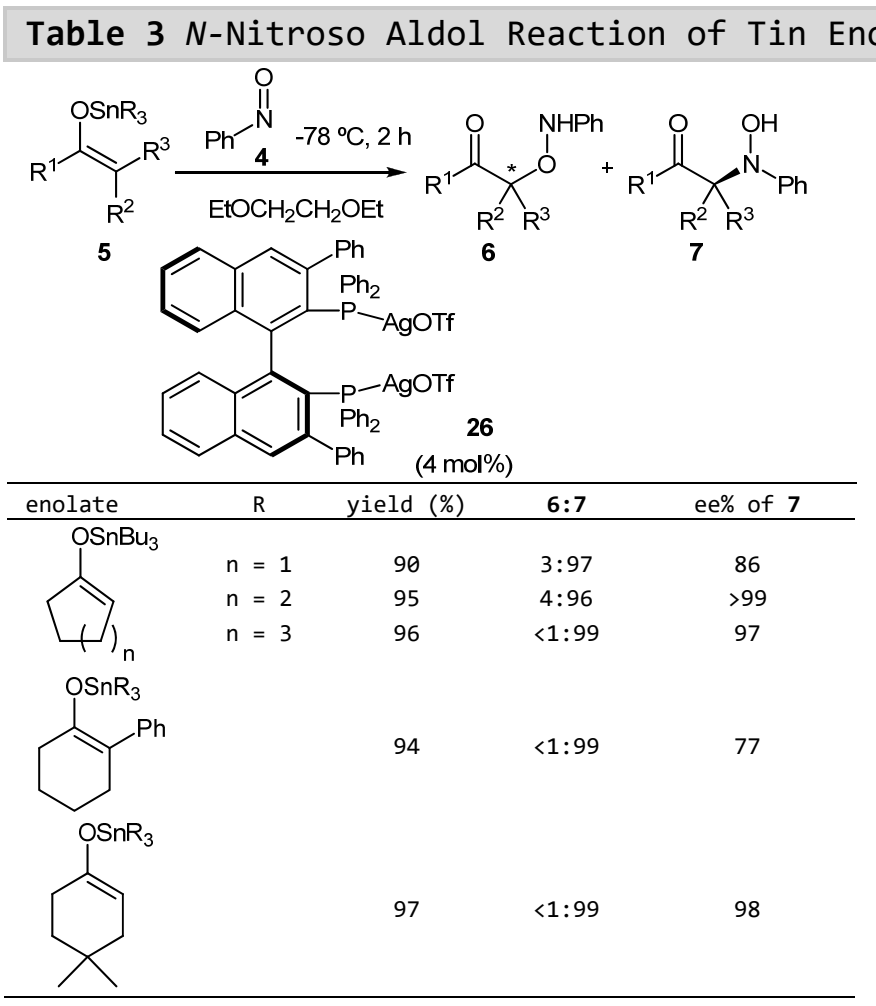

a Reactions were conducted with 1.0 equiv of nitrosobenzene and 1.0 equiv of tin enolate.

Alkenyl trichloroacetates have been reported to undergo $N$-nitroso aldol reactions with nitrosobenzene using dibutyltin dimethoxide as a catalyst, which is regenerated by methanol. ${ }^{28}$ However, no chiral version of the reaction has been developed. On the other hand, the same group reported the catalytic enantioselective $N$-nitroso aldol reaction of $\gamma, \delta$-unsaturated $\delta$-lactones 27 using a chiral tin bromide ethoxide as a catalyst generated in situ from the corresponding tin dibromide 29. ${ }^{29}$ Notably, the reaction took place smoothly providing high enantioselectivities with nitrosoarenes $\mathbf{2 8}$ bearing a bulky substituent at ortho-position; on the contrary, with nitrosobenzene $(\mathbf{2 8}, \mathrm{R}=\mathrm{H})$ both yield and enantioselectvity were low (Table 4). In general, no traces of the $O$-adduct were detected. With $\beta, \gamma$-unsaturated $\gamma$-lactones lower chemical yields and enantioselectivities were obtained. 
Table $4 \mathrm{~N}$-Nitroso Aldol Reaction of $\gamma, \delta$-unsaturated $\delta$-lactones ${ }^{a}$

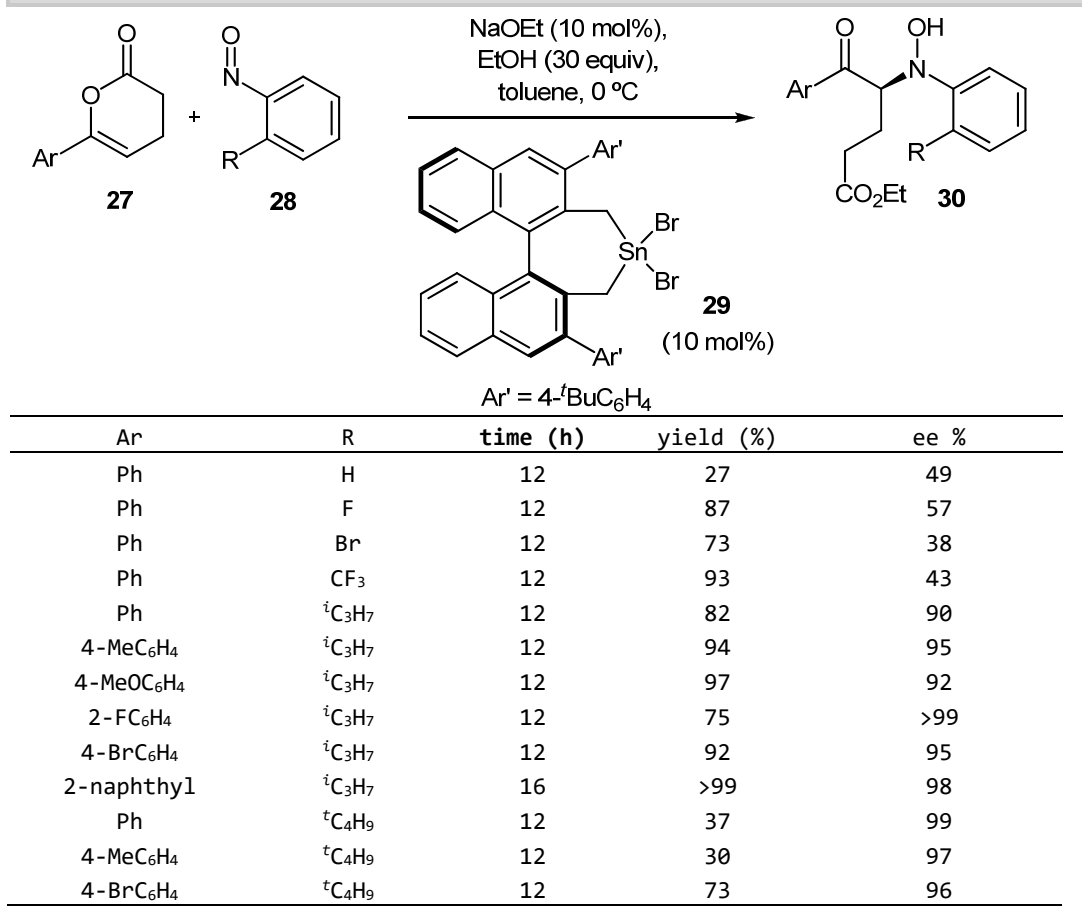

a Reactions were conducted with 1.0 equiv of nitrosoarene and 2.0 equiv of $\gamma, \delta$-unsaturated $\delta$-lactone.

The authors suggested the catalytic cycle illustrated in Scheme 8. According to this proposal the reaction of dibromide $\mathbf{2 9}$ with sodium ethoxide generates in situ the real catalyst $\mathbf{3 1}$ which reacts with $\mathbf{2 7}$ to form tin enolate $\mathbf{3 2}$. Further nitro aldol reaction between $\mathbf{3 2}$ and $\mathbf{2 8}$ affords intermediate $\mathbf{3 3}$ which regenerates the catalyst upon releasing product $\mathbf{3 0}$.

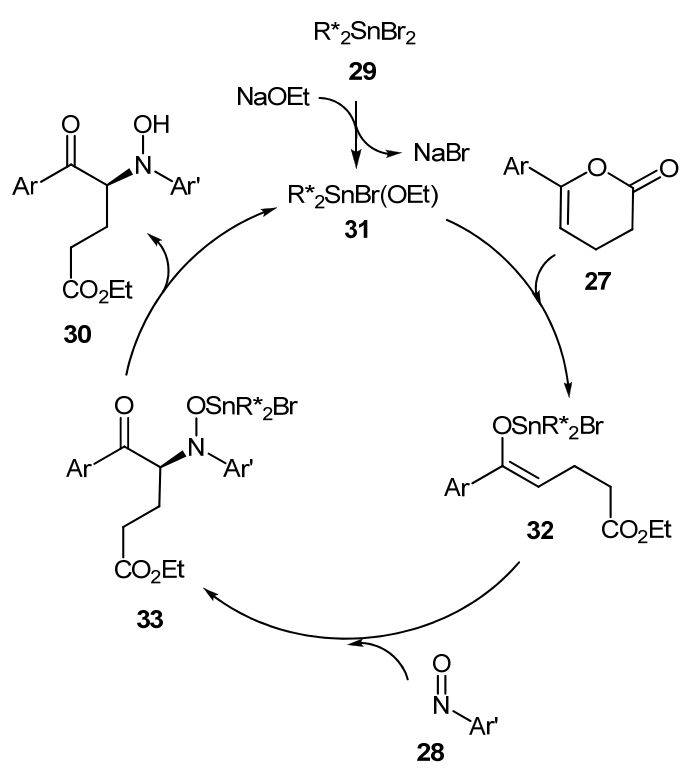

\section{Scheme 8.}

A highly efficient catalytic asymmetric hydroxyamination of $\mathrm{N}$-unprotected-3substituted oxindoles $\mathbf{3 4}$ has been reported by Feng and co-workers. ${ }^{30}$ The reaction was 
carried out with a 1:1.5 complex formed in situ from scandium(III) triflate and bis-Noxide 35. The reaction conditions were tolerant with several functional groups and provided high yields and enantioselectivities in a totally $N$-selective nitroso aldol reaction (Table 5). The reaction leading to highly enantioenriched quaternary centers was carried out with a variety of nitrosoarenes demonstrating a good versatility in both oxindoles and nitrosoderivatives.

\section{Table $5 \mathrm{~N}$-Nitroso Aldol Reaction of Oxindoles ${ }^{a}$}

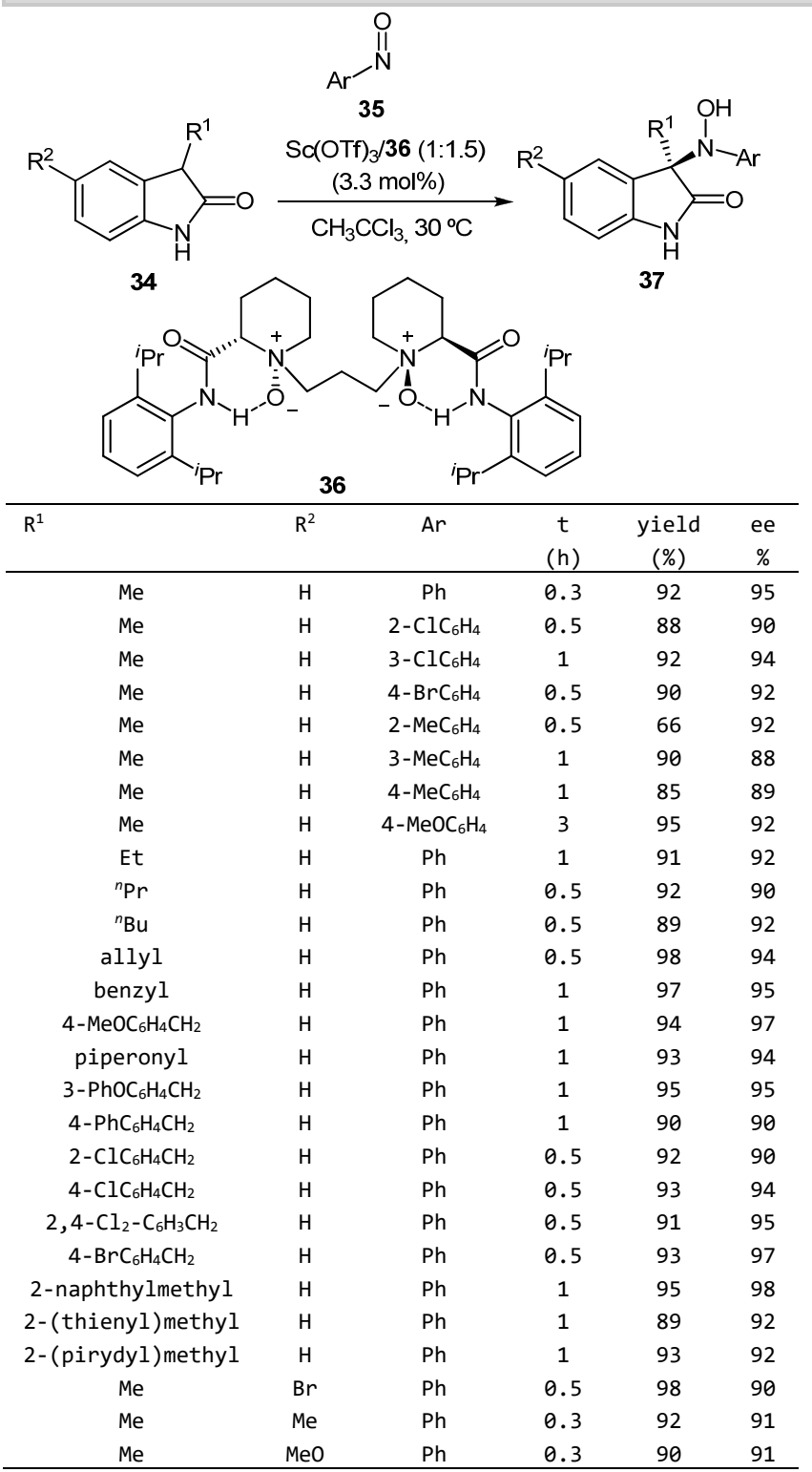

a Reactions were conducted with 1.1 equiv of nitrosobenzene and 1.0 equiv of oxindole.

Ligand 39, rather similar to 36, was employed in the magnesium-catalyzed asymmetric hydroxyamination of cyclic and acyclic $\beta$-ketoesters 38 (Scheme 9) ${ }^{31}$ In all cases complete $N$-selectivity as well as high yields and enantioselectivities were observed. 
The nitrosoformate derivative was generated in situ from the corresponding carbamate 13 and manganese(IV) oxide. ${ }^{32}$ In contrast to the reaction catalyzed by copper(II) triflate (see above Scheme 4), when bisoxazolines such as PhBox 14 were used as ligands considerably lower enantiomeric excesses were obtained although the $N$-adducts were predominant (15:1 N/O ratio). The reaction was also extended to benzyloxycarbamate $\mathbf{1 7}$ without substantial loss of any selectivity.
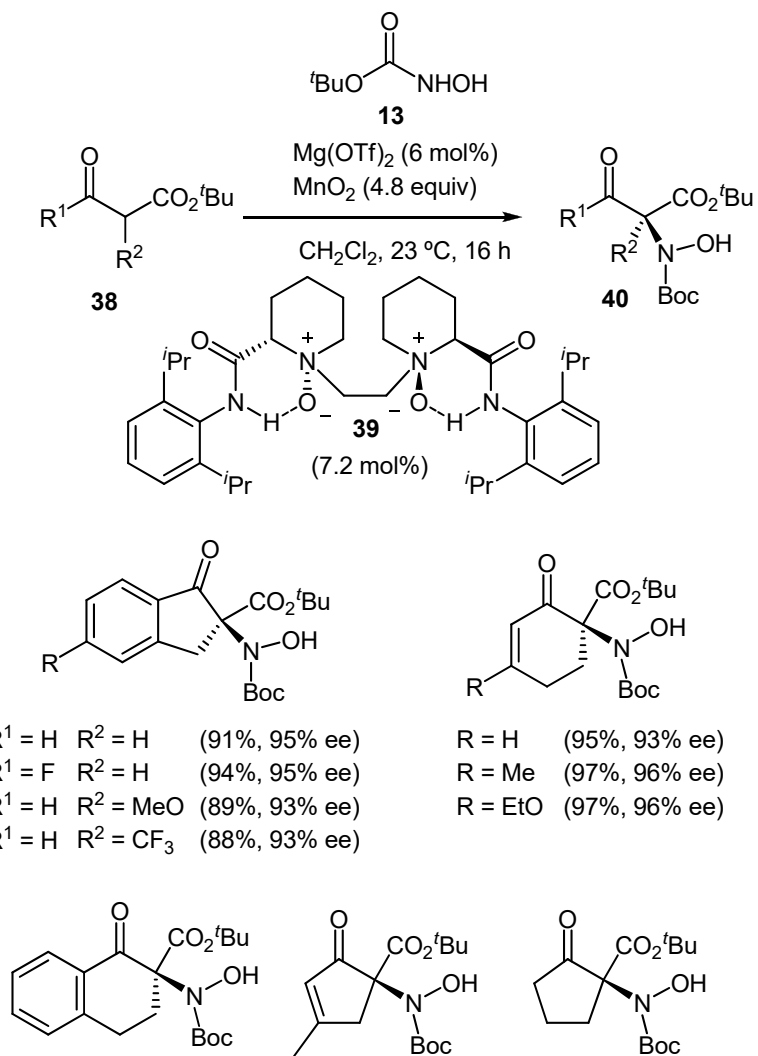<smiles>CCCCC(=O)N(O)C1(C(=O)OC(C)(C)C)CC(C)=CC1=O</smiles><smiles>O=C(O)OC(=O)N(O)C1(C(=O)OCc2ccccc2)CCCC1=O</smiles>

$(95 \%, 86 \%$ ee $)$ $(83 \%, 93 \%$ ee $)$

$(92 \%, 85 \%$ ee $)$

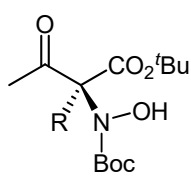

$\mathrm{R}=\mathrm{Me}$

$\mathrm{R}=\mathrm{PhCH}_{2}$

$\mathrm{R}=$ allyl

$\mathrm{R}=$ propargyl $(82 \%, 94 \%$ ee $)$<smiles>CC(C)(C)OC(=O)N(O)[C@](C)(C(=O)/C=C/c1ccccc1)C(=O)OC(C)(C)C</smiles>

$(89 \%, 87 \%$ ee $)$

\section{Scheme 9.}

Liu and co-workers reported an enantioselective tandem conjugate addition / $N$-nitroso aldol reaction catalyzed by copper(II) triflate and phosphoramidite $\mathbf{4 2}$ in the presence of equimolar amounts of diethylzinc. ${ }^{33}$ The first step of the reaction consisted on the conjugate addition of ethyl zinc to $\mathbf{4 1}$. The intermediate chiral zinc enolate formed after the addition was trapped with nitrosobenzene $\mathbf{4}$ through a typical nitroso aldol reaction 
to give $\mathbf{4 3}$ as a mixture of isomers. The reaction was completely $N$-selective but low diastereoselectivites and moderate enantioselectivities were obtained (Scheme 10).

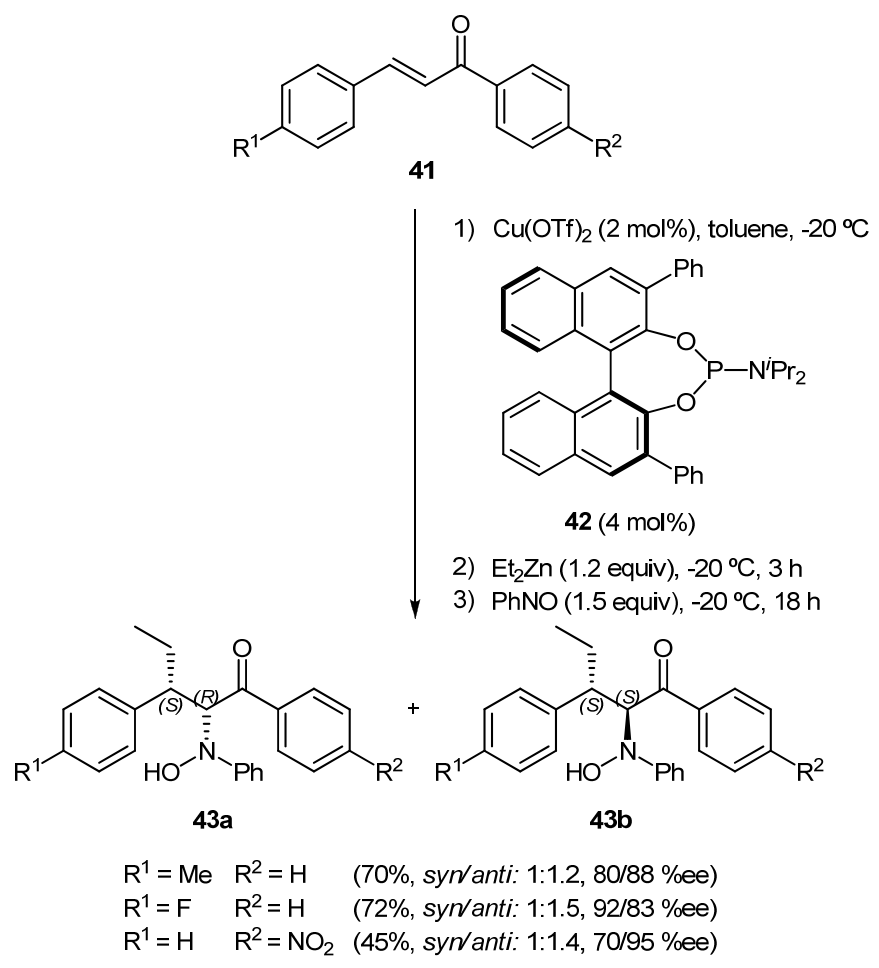

\section{Scheme 10.}

\section{Organocatalyzed Reactions}

The first enantioselective organocatalytic nitroso aldol reaction was described simultaneously by Zhong, ${ }^{34}$ MacMillan $^{35}$ and Hayashi ${ }^{36}$ in 2003. Condensation of nitrosobenzene $\mathbf{4}$ with aldehydes $\mathbf{4 4}$ in the presence of a catalytic amount of L-proline 45 afforded $\alpha$ - aminoxyaldehydes 46 in high yield and enantioselectivity (Scheme 11). Compounds $\mathbf{4 6}$ are oligomeric in solution and were most conveniently isolated as the corresponding primary alcohols after reduction with sodium borohydride. Considerable variation of bulkiness in substrates did not affect the enantiomeric excess. Notably, even though due to operational convenience the use of $5 \mathrm{~mol} \%$ of catalyst ensure high efficiency, the reaction can be conducted with just $0.5 \mathrm{~mol} \%$ of L-proline without substantial loss of enantiocontrol $(18 \mathrm{~h}, 68 \%, 94 \%$ ee for $\mathrm{R}=\mathrm{Me}){ }^{35}$ 


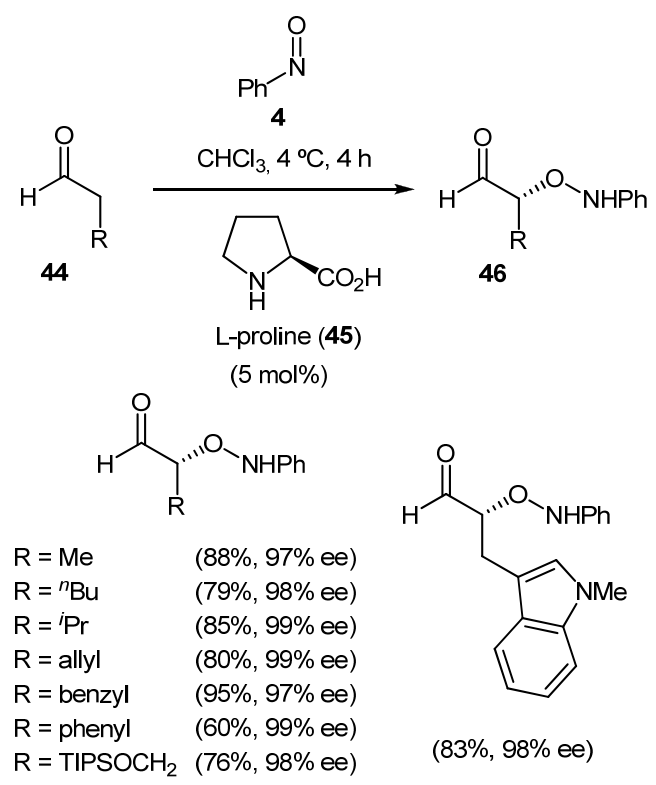

\section{Scheme 11.}

The enhanced Brønsted basicity of the nitrogen atom of L-proline was suggested to be the ultimate responsible for $O$-addition according to the model illustrated in Figure 2, corresponding to typical enamine catalysis. ${ }^{34,35}$<smiles>O=C(O)C1CCN(c2ccccc2)CCC1=O</smiles>

Figure 2. Model of addition for L-proline catalyzed nitroso aldol reaction with aldehydes

One year later, Córdova and co-workers reported the proline-catalyzed direct $\alpha$ aminoxylation of different aliphatic ketones 47 (Table 6). ${ }^{37,38}$ In the case of unsymmetrical ketones the reaction occurred exclusively on the methylene carbon. For acyclic ketones small amounts of the corresponding $\mathrm{N}$-adducts were obtained (with the exception of allyl methyl ketone in which $\mathrm{N}$-adduct was predominant) and only cyclohexanone showed to be completely $O$-selective. This result was simultaneously confirmed by Hayashi and co-workers ${ }^{39}$ who also demonstrated that slow addition of nitrosobenzene made it unnecessary to use a large excess of ketone and only 2 equiv was enough. A further comprehensive study with cyclic six-membered ketones demonstrated that the reaction was completely $O$-selective for those substrates. ${ }^{40}$ This study also showed a moderate diastereoselectivity with 3- or 4-substituted cyclohexanones that could lead to mixtures of isomers. In all cases, however, $O$ - 
selectivity and excellent enantioselectivity were maintained. Interestingly, trans-4-tertbutyldimethylsiloxy-L-proline $\mathbf{4 8}$ displayed a greater catalytic activity when compared with L-proline (Table 6). ${ }^{41}$ In fact, the reaction also proceeded with high enatioselectivities (up to 96-99\% ee) with trans-4-hydroxy-L-proline immobilized onto Merrifield-type resins. In general, reaction rates for cyclic six-membered ketones were higher for the immobilized catalyst 49 than those reported for L-proline. ${ }^{42}$ Compound $\mathbf{5 0}$ derived from isosteviol has also been checked as a catalyst but enantioselectivities were lower than other catalysts in the case of aldehydes; however, higher ee value was obtained with cyclohexanone. ${ }^{43}$

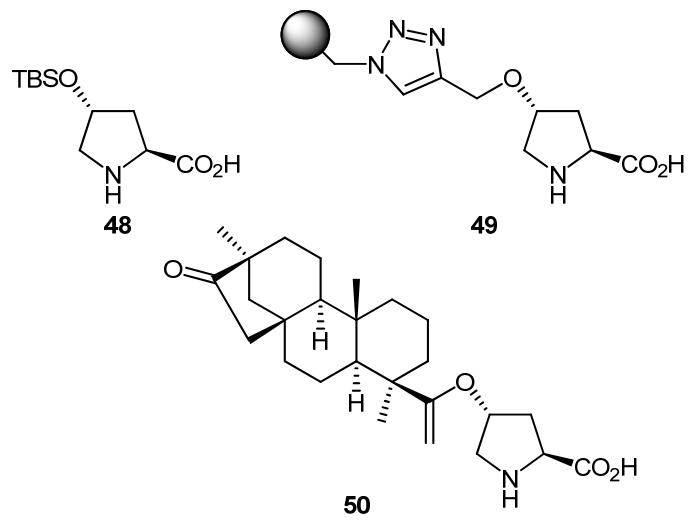

Figure 3. 4-substituted L-prolines

The same transition sate model operates for the reaction of both aldehydes and ketones. Simple DFT calculations made with ketones supported the same model illustrated in Figure 2 for aldehydes. ${ }^{38}$ Non-linear effects were not observed so, quite likely a single proline molecule is involved in the mechanism. Houk and Cheong demonstrated that proline catalysis takes place via enamine attack on the oxygen of the nitrosobenzene monomer, following a similar model to that illustrated in Figure 2, but with a simultaneous proton transfer from the carboxylic acid. ${ }^{44}$ Calculations with highly substituted meso-cyclohexanones, which underwent asymmetric desymmetrization through a nitroso aldol reaction catalyzed by L-proline, ${ }^{45}$ demonstrated that the observed diastereoselectivity is due to the polar groups at $\gamma$-position of the ketone and to differences in conformations. ${ }^{46}$ 
Table 6 Nitroso Aldol Reaction of ketones catalyzed by L-proline derivatives ${ }^{a}$

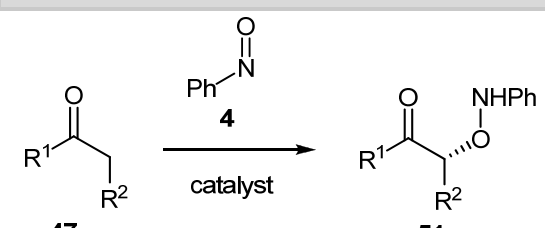

\begin{tabular}{|c|c|c|c|c|c|c|c|c|c|}
\hline 46 & Cat & $\begin{array}{l}\text { Cat. } \\
\text { mol\% }\end{array}$ & solvent & $\mathrm{T}(\stackrel{\mathrm{o}}{ } \mathrm{C})$ & $t(h)$ & $\begin{array}{c}\text { yield } \\
(\%)\end{array}$ & $0 / N$ & $\begin{array}{l}\text { ee } \% \\
\text { of } 50\end{array}$ & Ref. \\
\hline & 45 & 20 & DMSO & rt & $2-3$ & 93 & $81: 19$ & $>99$ & 37 \\
\hline & 45 & 10 & DMF & 0 & 2 & 73 & $55: 45$ & $>99$ & 39 \\
\hline
\end{tabular}<smiles>CCC(=O)CC</smiles>

4520 DMSO rt $2-3$

H<smiles>CC(=O)CC(C)C</smiles>

$45 \quad 20$

DMSO

$r t$

66

$55: 45$

r<smiles>O=C1CCCCC1</smiles>

$45 \quad 20$

DMSO

$45 \quad 20 \quad$ DMSO

$45 \quad 30 \quad$ DMF

$45 \quad 10 \quad$ DMF

$48 \quad 10$

$49 \quad 20$

DMF

DMF

buffer ${ }^{b} \quad r t$<smiles>O=C1CCC2(CC1)OCCO2</smiles>

$45 \quad 20$

DMSO

DMF

DMF

$\begin{array}{ccc}45 & 5 & \text { DMF } \\ 49 & 20 & \text { DMF }\end{array}$<smiles>CC1(C)CCC(=O)CC1</smiles>

$45 \quad 10$

DMF

$\begin{array}{ll}48 & 10 \\ 49 & 20\end{array}$<smiles>O=C1CCNCC1</smiles>

\section{5} 10 DMF

0

60

45

$1: 0$

$>99$<smiles>CC(C)(C)OC(=O)N1CCC(=O)CC1</smiles>

\section{5}

10

DMF

0

24

41

$1: 0$

$>99$<smiles>O=C1CCSCC1</smiles> 
The synthetic utility of the reaction has been demonstrated by preparing $(+)-$ panepophenanthrin 54 from adduct 53 -obtained using D-proline as a catalyst- in 11 steps and $18.2 \%$ overall yield (Scheme 12$).{ }^{47}$

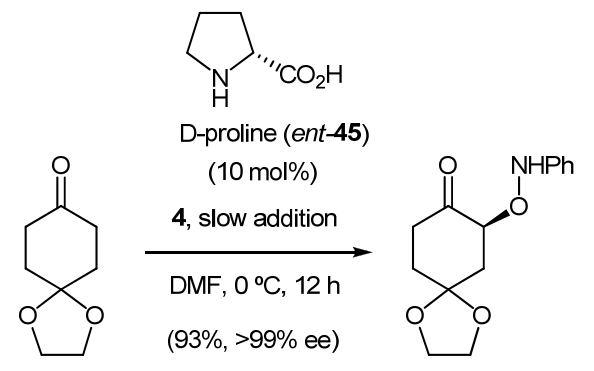

52

53

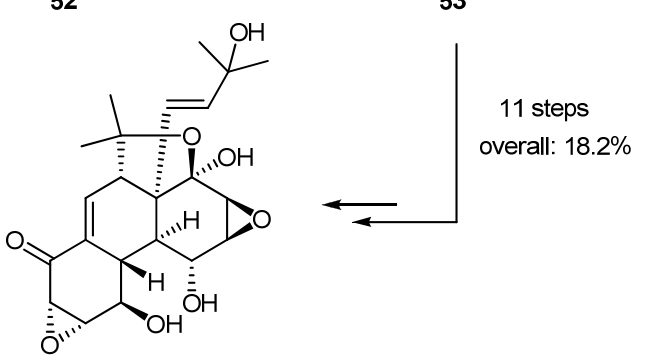

(+)-panepophenanthrin (54)

\section{Scheme 12}

Four-membered cyclic ketones, i.e. cyclobutanones presented an unexpected behaviour when reacted with nitrosobenzene in the presence of L-proline. 3-Substitued cyclobutanones 55 underwent enantioselective desymmetrization to give 5-hydroxy- $\gamma$ lactams 57 instead of expected $\alpha$-aminoxylated adduct; similar results were obtained when pyrrolidinyl tetrazol $\mathbf{5 6}$ was used as a catalyst (Table 7). ${ }^{48}$

\section{Table 7 Desymmetrization of 3-substituted cyclobutanones ${ }^{2}$}

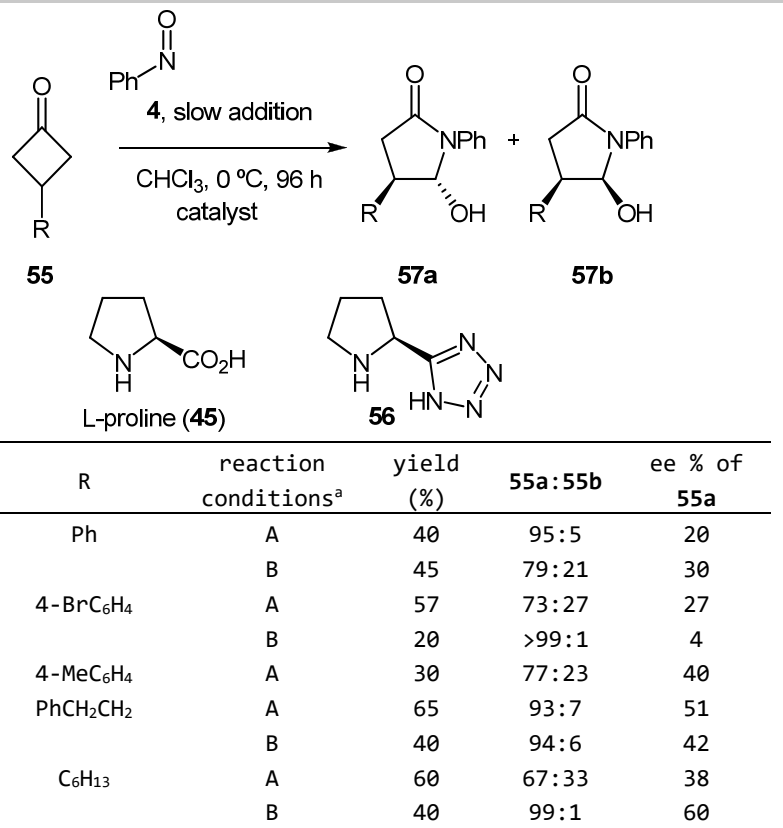




$\begin{array}{lllll}\text { cyclohexyl } & \text { A } & 48 & 85: 15 & 37 \\ & \text { B } & 41 & 72: 28 & 56\end{array}$

a Conditions A: 5.0 equiv of cyclobutanone, 1.0 equiv of nitrosobenzene and 30 mol\% of 45 . Conditions B: 1.0 equiv of cyclobutanone, 3.0 equiv of nitrosobenzene and $20 \mathrm{~mol} \%$ of 56 .

In general, good trans-selectivities were observed but moderate yields and enantioselectivities were obtained. The proposed mechanism for the observed ring expansion of compounds 53 is illustrated in Scheme 12. After initial $\alpha$-oxyamination of the enamine $\mathbf{5 6}$ formed from $\mathbf{5 3}$, the iminium intermediate $\mathbf{5 7}$ undergoes an intramolecular attack leading to bicycle 58 that rearranges into iminium 59, which regenerates the catalyst after releasing the product.

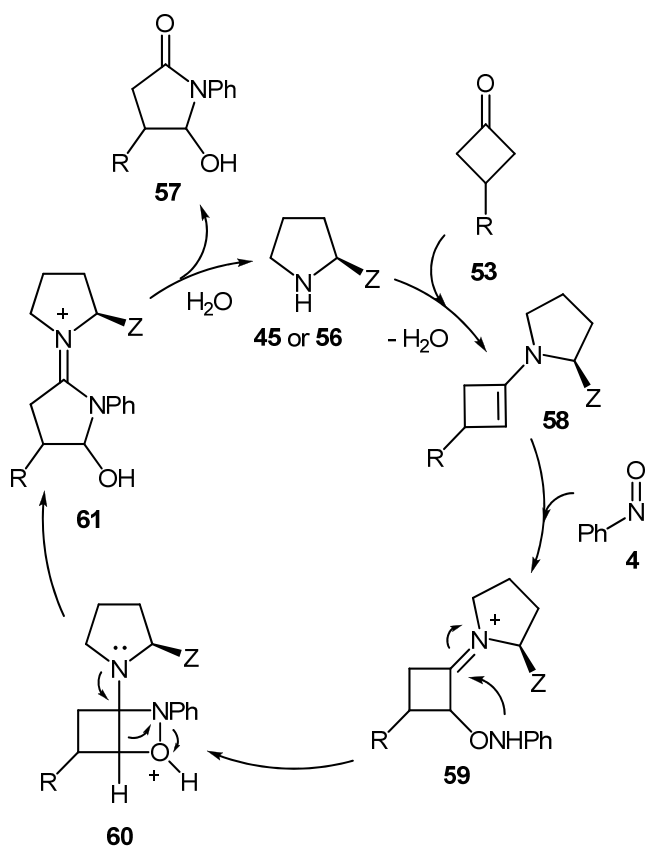

\section{Scheme 12}

Asymmetric synthesis of 3-hydroxy-2-alkanones 62 was achieved through a tandem $O$ selective nitroso aldol reaction of aldehydes followed by subsequent chemoselective homologation with diazomethane (Scheme 13). ${ }^{49}$ The reaction proceeded with moderate yields and excellent enantioselectivities. 


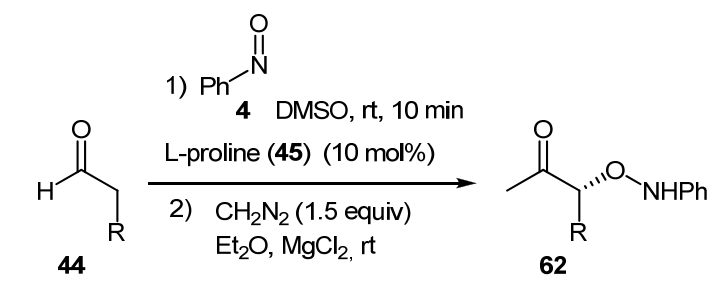

$\mathrm{R}=\mathrm{Me} \quad(40 \%, 97 \%$ ee $) \quad \mathrm{R}=4-\mathrm{BrC}_{6} \mathrm{H}_{4} \mathrm{CH}_{2} \quad(57 \%, 98 \%$ ee $)$

$\mathrm{R}={ }^{n} \mathrm{C}_{5} \mathrm{H}_{11} \quad(46 \%, 98 \%$ ee $) \quad \mathrm{R}=\mathrm{MeSCH}_{2} \quad(43 \%, 97 \%$ ee $)$

$\mathrm{R}={ }^{n} \mathrm{C}_{10} \mathrm{H}_{21} \quad(46 \%, 98 \%$ ee $) \quad \mathrm{R}=\mathrm{TBSOCH}_{2} \mathrm{CH}_{2}(42 \%, 99 \%$ ee $)$

$\mathrm{R}={ }^{i} \mathrm{Pr} \quad(55 \%, 98 \%$ ee $) \quad \mathrm{R}=\mathrm{BnOCH}_{2} \mathrm{CH}_{2} \quad(41 \%, 95 \%$ ee $)$

$\mathrm{R}=$ benzyl $\quad(60 \%, 97 \%$ ee $)$

Scheme 13

Optically active 1,2-oxazines $\mathbf{6 5}$ were prepared in good chemical yields and excellent diastereo- and enantioselectivities through a dual-organocatalyzed asymmetric $\alpha$ aminoxylation/aza-Michael/aldol condensation cascade (Table 8)..$^{50}$

Table 8 a-aminoxylation/aza-Michael/aldol condensation cascadea

$\begin{array}{cccccc} & & & & \\ & & & & \end{array}$

a Reactions were conducted with 1 equiv of nitrosobenzene, 3 equiv of aldehyde 44 and 5 equiv of aldehyde 61

The general scheme for the cascade reaction is depicted in Scheme 14. Two organocatalysts were used in a one-pot procedure since L-proline was showed to be ineffective as the iminium catalyst required for the second step of the reaction. The loading of catalyst 64 was resized to $30 \mathrm{~mol} \%$ in order to accelerate the aza-Michael reaction. 


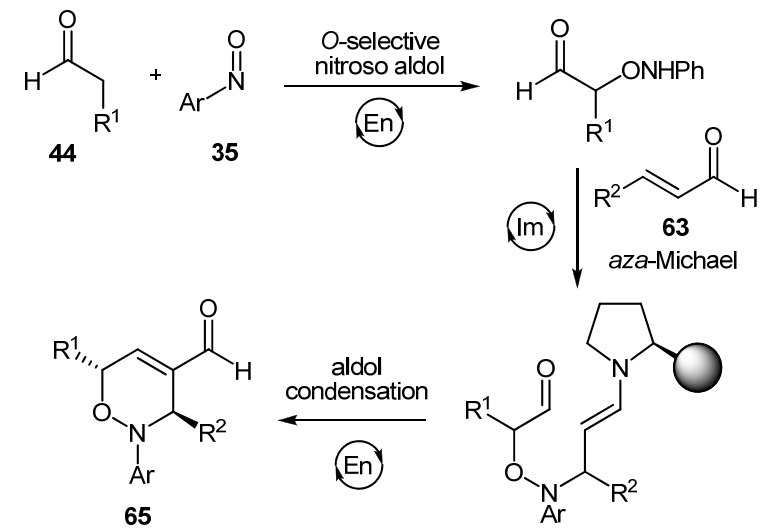

\section{Scheme 14}

In two simultaneous papers Wang ${ }^{51}$ and Huang reported proline-catalyzed direct asymmetric $\alpha$-aminoxylation of aldehydes and ketones using ionic liquid 1-n-butyl-3methylimidazolium tetrafluoroborate as a solvent. The reaction was totally $O$-selective and proceeded with high yields and enantioselectivities (Table 9). Interestingly, the ionic liquid containing the catalyst was reused four ${ }^{51}$ and $\operatorname{six}^{52}$ times without substantial loss of efficiency.

Table 9 a-Aminoxylation reaction of aldehydes and ketones in ionic liquida

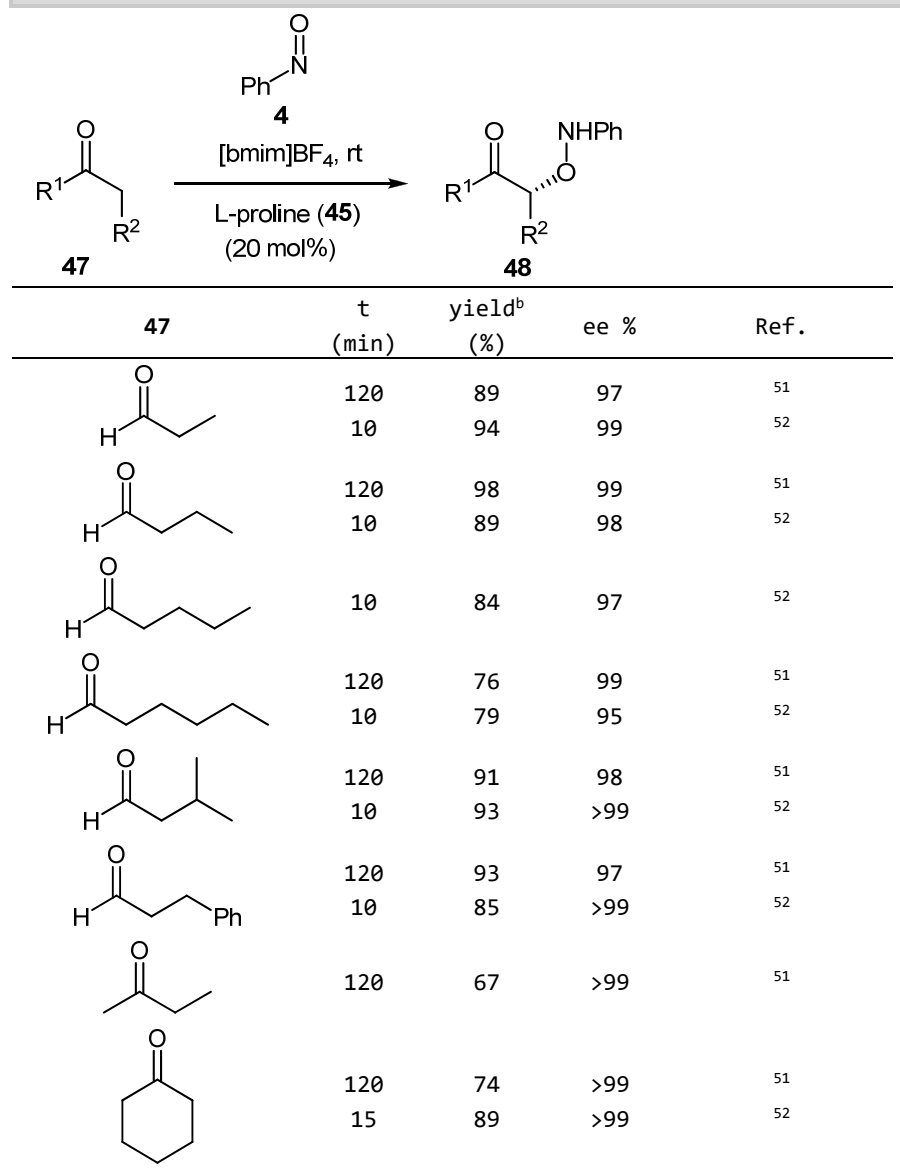




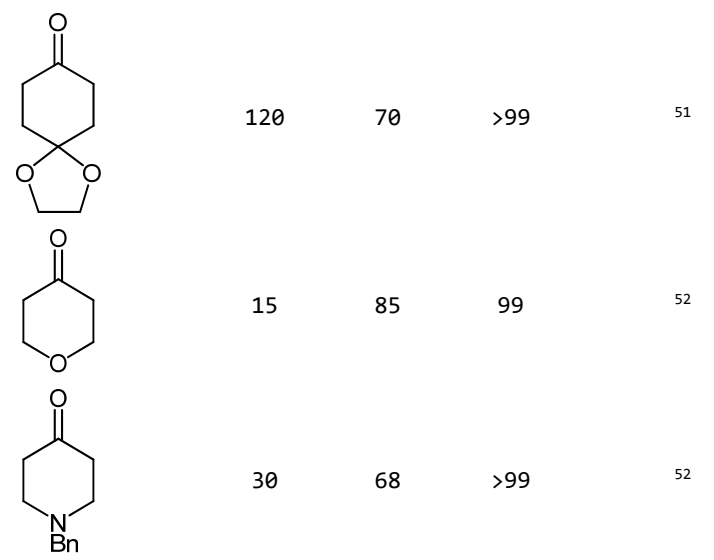

a Reactions were conducted with 1 equiv of nitrosobenzene and 3 equiv (Ref. ${ }^{51}$ ) or 2 equiv (Ref. ${ }^{52}$ ) of aldehyde or 3 equiv (Ref. ${ }^{51}$ and ${ }^{52}$ ) of ketone. b Isolated yield (in the case of aldehydes of the alcohol after reduction with sodium borohydride)

Proline was also incorporated covalently to the ionic liquid by preparing imidazolium ion-tagged prolines $66^{53}$ and $67 .{ }^{54}$ As an example the $\alpha$-aminoxylation of 3methylbutanal 68 in a ionic liquid as a solvent afforded, after in situ reduction, the corresponding diol 69 in good yield and high enantioselectivity for both catalysts (Scheme 15). The reaction catalyzed by 66 was also reported for cyclic six-membered ketones $99 \%$ ee being obtained. Catalyst 66 was reused up to seven times in the $\alpha$ aminoxylation of cyclohexanone and $>99 \%$ ee was obtained in all runs. ${ }^{53}$

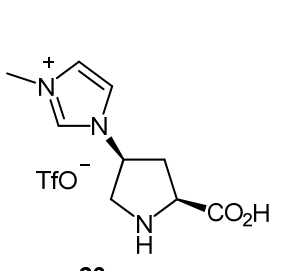

66

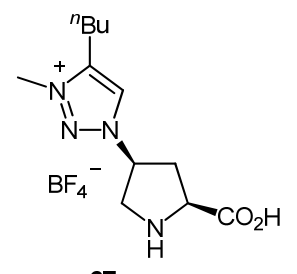

67<smiles>CC(C)CC=O</smiles>

catalyst $66,5 \mathrm{~min}: \quad(85 \%, 99 \%$ ee $)$ catalyst $67,15 \mathrm{~min}:(83 \%, 96 \%$ ee)

\section{Scheme 15}

The addition of urea $\mathbf{7 0}^{55}$ and thioureas $\mathbf{7 1}$ and $\mathbf{7 2}^{56}$ (Figure 4) as co-catalysts to the nitroso aldol reaction catalyzed by L-proline resulted in higher reaction rates in more benign solvents. 
<smiles>CNC(=S)Nc1cc(C(F)(F)F)cc(C(F)(F)F)c1</smiles>

Figure 4. Co-catalysts for the proline-catalyzed $\alpha$-Aminoxylation reaction of aldehydes

O-Selectivity as well as high yields and enantioselectivities are maintained (Table 10). Additional experiments including comparison with immobilized L-proline and soluble trans-4-(tertbutyldimethylsiloxy)-L-proline demonstrated that the role of urea $\mathbf{7 0}$ is not to facilitate the dissolution of the catalyst. ${ }^{55}$ In agreement with the observations derived from those studies it has been suggested that co-catalyst $\mathbf{7 0}$ promotes enamine formation by interacting with an intermediate productive catalytic oxazolidinone. On the other hand, compounds $\mathbf{7 1}$ and $\mathbf{7 2}$ have been suggested ${ }^{56}$ to promote favorable Hbond interactions in the transition state of the reaction between the carboxyl group of the catalyst and the $\mathrm{NH}$ groups of the bisthiourea

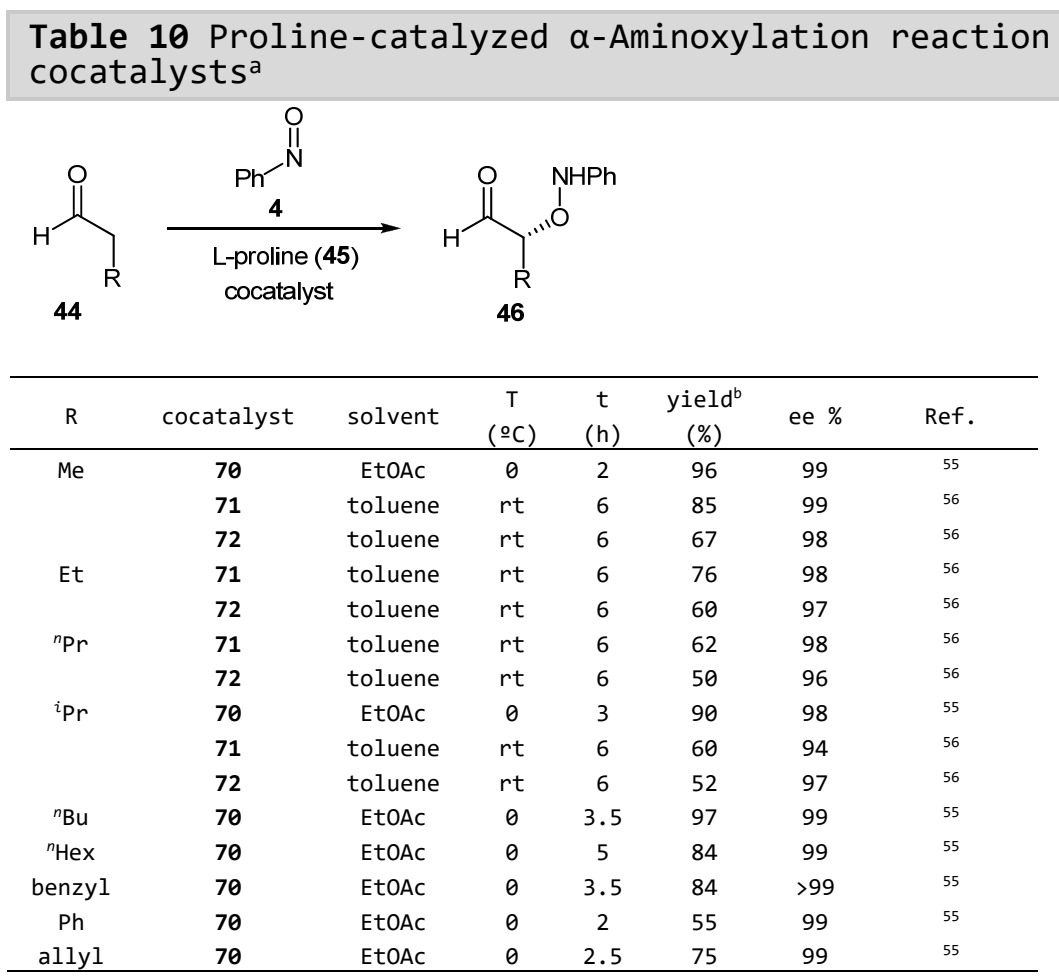


a Reactions were conducted with 1 equiv of nitrosobenzene and 3 equiv (Ref. ${ }^{55}$ ) or 2 equiv (Ref. ${ }^{56}$ ) of aldehyde. Catalyst and co-catalyst were added in 5 mol\% (Ref. ${ }^{55}$ ) or $10 \mathrm{~mol} \%$ (Ref. ${ }^{56}$ ). ${ }^{b}$ Isolated yield of the alcohol after reduction with sodium borohydride

In addition to proline, other pyrrolidine-derived organocatalysts can be employed to catalyze an $O$-selective nitroso aldol reaction of aldehydes and ketones, the most used being pyrrolidinyl tetrazole $\mathbf{5 6}$ which showed excellent selectivity results rather similar to proline. ${ }^{57}$ When 2-nitrosotoluene was employed in combination with $\mathbf{5 6}$ the addition time of the nitroso compound is greatly reduced in comparison with that for prolinecatalyzed reactions thus avoiding the use of excess ketone. ${ }^{58}$ Compound $\mathbf{5 6}$ has also been used successfully in the asymmetric desymmetrization of highly substituted mesocyclic ketones through tandem aminoxylation/O-N bond heterolysis reactions. ${ }^{45}$

Catalyst 56 has been employed in tandem processes involving $O$-selective nitroso aldol reactions. Tandem $O$-nitroso aldol / Michael reaction was reported by Yamamoto and co-workers with $\alpha, \beta$-unsaturated cyclic ketones 73 (Scheme 16). ${ }^{59}$ The methodology was applicable to various aromatic nitroso compounds. In a similar way to that observed for the direct $\alpha$-aminoxylation (see above) higher catalytic activity was observed with trans-4-tert-Butyldimethylsiloxy-1-proline 48 when compared with both 56 and Lproline 45. ${ }^{41}$ The observed regioselectivity and the mechanism of the reaction was studied by DFT methods. ${ }^{60}$ Calculations showed that the $O$-selective channel was much more energetically favorable then the $N$-selective channel. Both transition states corresponding to nitroso aldol and subsequent Michael addition had very similar barriers (5.37 and $5.43 \mathrm{kcal} / \mathrm{mol}$, respectively).

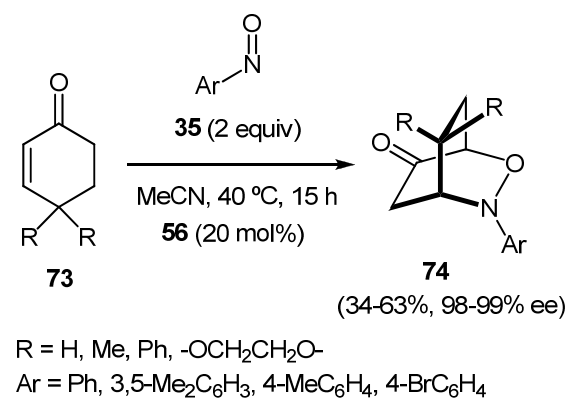

\section{Scheme 16}

A sequential $O$-nitroso aldol and Grignard addition process catalyzed by $\mathbf{5 6}$ allowed the preparation of 1,2-diols in high diastereo- and enantioselectivities. ${ }^{61}$ The process was made sequentially and the presence of benzoic acid was required in the first step for facilitating enamine formation. Since DMSO was showed to be more adequate for the nitroso aldol reaction but not suitable for the Grignard reaction, it was necessary to make an intermediate extraction with pentane to use the product for the next reaction 
without any purification (Scheme 17). The N-O bond was cleaved by the organometallic reagent and the presence of the ate complex of $\mathrm{CeCl}_{3} \cdot 2 \mathrm{LiCl}$ was crucial for the high yields and selectivities. Similar results were obtaine dwith L-proline as catalyst. In some cases the use of organolithium R'Li derivatives increased the chemical yield.
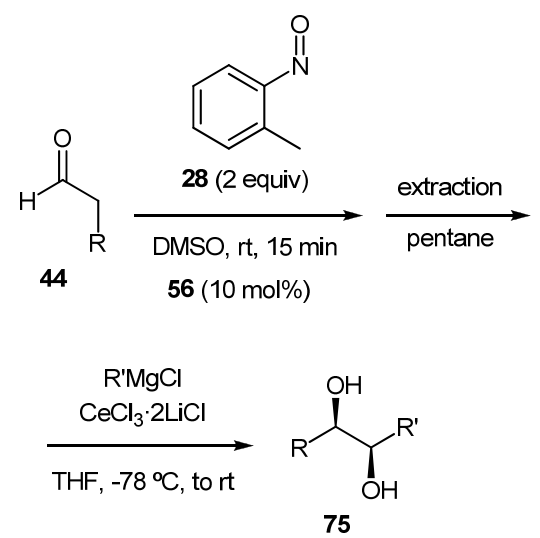

$$
\begin{aligned}
& \mathrm{R}={ }^{i} \mathrm{Pr} \quad \mathrm{R}=\mathrm{Me} \quad(63 \%, \mathrm{dr} 93: 7,97 \% \text { ee }) \\
& \mathrm{R}={ }^{i} \mathrm{Pr} \quad \mathrm{R}=\mathrm{Et} \quad(62 \%, \mathrm{dr} 95: 5,96 \% \text { ee }) \\
& \mathrm{R}={ }^{i} \mathrm{Pr} \quad \mathrm{R}=\text { allyl } \quad(73 \%, \mathrm{dr} 91: 9,96 \% \text { ee }) \\
& \mathrm{R}={ }^{i} \mathrm{Pr} \quad \mathrm{R}=\text { benzyl } \quad(77 \%, \mathrm{dr}>99: 1,>99 \% \text { ee }) \\
& \mathrm{R}={ }^{i} \mathrm{Pr} \quad \mathrm{R}={ }^{i} \mathrm{Pr} \quad(75 \%, \mathrm{dr} 95: 5,98 \% \text { ee }) \\
& \mathrm{R}={ }^{i} \mathrm{Pr} \quad \mathrm{R}={ }^{t} \mathrm{Bu} \quad(24 \%, \mathrm{dr}>99: 1,97 \% \text { ee }) \\
& \mathrm{R}={ }^{i} \mathrm{Pr} \quad \mathrm{R}=\mathrm{Ph} \quad(65 \%, \mathrm{dr}>99: 1,96 \% \text { ee }) \\
& \mathrm{R}={ }^{i} \mathrm{Pr} \quad \mathrm{R}=4-\mathrm{FC}_{6} \mathrm{H}_{4} \quad(74 \% \text {, dr } 95: 5,96 \% \text { ee }) \\
& \mathrm{R}={ }^{i} \mathrm{Pr} \quad \mathrm{R}=4-\mathrm{MeOC}_{6} \mathrm{H}_{4} \quad(71 \%, \mathrm{dr} 96: 4,97 \% \text { ee }) \\
& \mathrm{R}={ }^{i} \mathrm{Pr} \quad \mathrm{R}=2 \text {-furyl } \quad(65 \% \text {, dr 94:6, 97\% ee) } \\
& \mathrm{R}={ }^{i} \mathrm{Pr} \quad \mathrm{R}=\mathrm{CH}_{2} \mathrm{CO}_{2}{ }^{t} \mathrm{Bu} \quad(45 \% \text {, dr 95:5, 93\% ee) } \\
& \mathrm{R}=\mathrm{Ph} \quad \mathrm{R}=\mathrm{Me} \quad(66 \%, \mathrm{dr} 93: 7,98 \% \mathrm{ee}) \\
& \mathrm{R}=\mathrm{Ph} \quad \mathrm{R}={ }^{n} \mathrm{Bu} \quad(62 \%, \mathrm{dr} 95: 5,>99 \% \text { ee }) \\
& \mathrm{R}=\mathrm{Ph} \quad \mathrm{R}=\text { allyl } \quad(76 \%, \mathrm{dr} 96: 4,99 \% \text { ee }) \\
& \mathrm{R}=\mathrm{Ph} \quad \mathrm{R}=\text { benzyl } \quad(72 \%, \mathrm{dr}>99: 1,>99 \% \text { ee }) \\
& \mathrm{R}=\mathrm{Ph} \quad \mathrm{R}={ }^{i} \mathrm{Pr} \quad(64 \%, \mathrm{dr}>99: 1,98 \% \text { ee }) \\
& \mathrm{R}=\mathrm{Ph} \quad \mathrm{R}={ }^{t} \mathrm{Bu} \quad(57 \%, \mathrm{dr}>99: 1,>99 \% \text { ee }) \\
& \mathrm{R}=\mathrm{Ph} \quad \mathrm{R}=\mathrm{Ph} \quad(61 \%, \mathrm{dr} 96: 4,98 \% \text { ee }) \\
& \mathrm{R}=\text { allyl } \mathrm{R}=\text { allyl } \quad(70 \%, \mathrm{dr} 92: 8,98 \% \text { ee }) \\
& \mathrm{R}=\text { allyl } \mathrm{R}=\text { benzyl } \quad(65 \%, \mathrm{dr}>99: 1,96 \% \text { ee }) \\
& \mathrm{R}=\text { allyl } \mathrm{R}={ }^{i} \mathrm{Pr} \quad(65 \% \text {, dr 91:9, 96\% ee) } \\
& \mathrm{R}=\text { allyl } \mathrm{R}=\mathrm{Ph} \quad(70 \%, \mathrm{dr} 96: 4,98 \% \text { ee })
\end{aligned}
$$

\section{Scheme 17}

When the nitroso aldol reaction catalyzed by $\mathbf{5 6}$ was carried out in the presence of a Brønsted acid $N$-selectivity was predominant. Thus, the reaction between aldehydes and nitrosoformates generated in situ from the corresponding protected hydroxylamines $\mathbf{1 3}$ and 17 catalyzed by 56 and in the presence of cathecol resulted in an efficient method for accessing $\beta$-(hydroxyamino)alcohols 76 (Scheme 18). ${ }^{62}$ 
1) $\mathrm{R}^{2}-\mathrm{NHOH}$

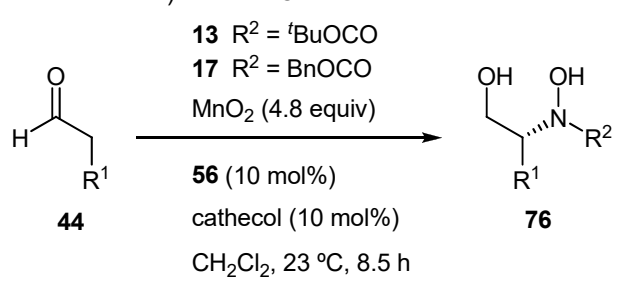

2) $\mathrm{NaBH}_{4}, \mathrm{MeOH}$,

$0^{\circ} \mathrm{C}, 40 \mathrm{~min}$

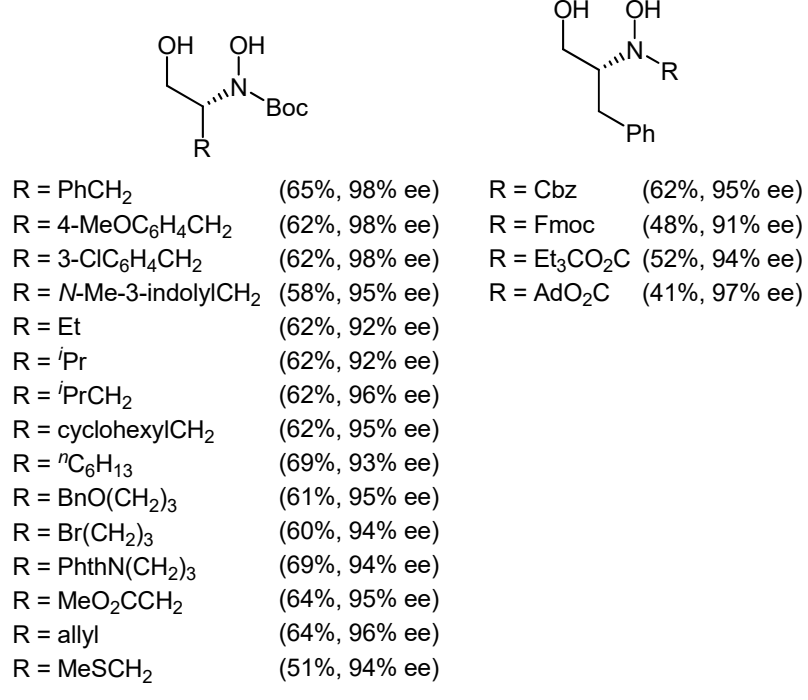

\section{Scheme 18.}

In the case of $\alpha$-branched aldehydes $\mathbf{7 7}$ the reaction with nitrosobenzene catalyzed by $\mathbf{5 6}$ afforded mixtures of $\mathrm{N}$ - and $\mathrm{O}$-adducts with predominance of the former (Table 11). ${ }^{63}$ The enantioselectivites were moderate for $\mathrm{N}$-adducts $\mathbf{7 8}$ and low for $\mathrm{O}$-adducts $\mathbf{7 9}$.

Table 11 Nitroso aldol reaction of $\alpha$-branched aldehydesa

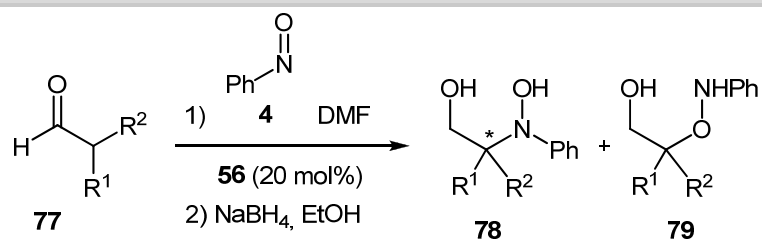

\begin{tabular}{ccccccc}
\hline $\mathrm{R}^{1}$ & $\mathrm{R}^{2}$ & $\begin{array}{c}\mathrm{t} \\
(\mathrm{h})\end{array}$ & $\begin{array}{c}\text { yield } \\
(\%)\end{array}$ & $\mathbf{7 8 : 7 9}$ & $\begin{array}{c}\text { ee } \% \\
\text { of } 78\end{array}$ & $\begin{array}{c}\text { ee } \% \\
\text { of 79 }\end{array}$ \\
\hline $\mathrm{Me}^{\mathrm{b}}$ & $\mathrm{PhCH}_{2}$ & 3 & 96 & $1: 1$ & 81 & 37 \\
$\mathrm{Me}^{\mathrm{c}}$ & $4-\mathrm{MeOC}_{6} \mathrm{H}_{4} \mathrm{CH}_{2}$ & 8 & 75 & $1.7: 1$ & 90 & 35 \\
$\mathrm{Me}^{\mathrm{c}}$ & $4-\mathrm{BrC}_{6} \mathrm{H}_{4} \mathrm{CH}_{2}$ & 3 & 98 & $1.4: 1$ & 86 & 45 \\
$\mathrm{Me}^{\mathrm{b}}$ & $\mathrm{Ph}$ & 24 & 83 & $20: 1$ & 64 & $\mathrm{n} . \mathrm{d}$. \\
$\mathrm{Me}^{\mathrm{b}}$ & $4-\mathrm{MeOC}_{6} \mathrm{H}_{4}$ & 24 & 65 & $10: 1$ & 45 & $\mathrm{n} . \mathrm{d}$. \\
$\mathrm{Me}^{\mathrm{c}}$ & $\mathrm{BnOCH}_{2}$ & 4 & 89 & $0.8: 1$ & 79 & 5 \\
$\mathrm{Me}^{\mathrm{b}}$ & $\mathrm{allyl}$ & 3 & 91 & $0.7: 1$ & 62 & 27 \\
$\mathrm{Me}^{\mathrm{b}}$ & $\mathrm{Et}$ & 12 & 76 & $1.7: 1$ & 70 & 8 \\
$\mathrm{Et}^{\mathrm{b}}$ & $\mathrm{PhCH} 2$ & 6 & 67 & $1.3: 1$ & 25 & 11 \\
$\mathrm{Et}^{\mathrm{b}}$ & ${ }^{n} \mathrm{Bu}$ & 12 & 55 & $0.6: 1$ & 5 & 2 \\
\hline
\end{tabular}

a Reactions were conducted with 1 equiv of nitrosobenzene and 2 equiv of aldehyde. ${ }^{b}$ Reaction carried out at 25 ㅇ․ c Reaction carried out at 0 으 
Complete $N$-selectivity with $\alpha$-branched aldehydes 77 was achieved using prolinamide 80 as a catalyst (Scheme 19). ${ }^{64}$ After 2-3 days of reaction modest values of enantioselectivity were obtained.

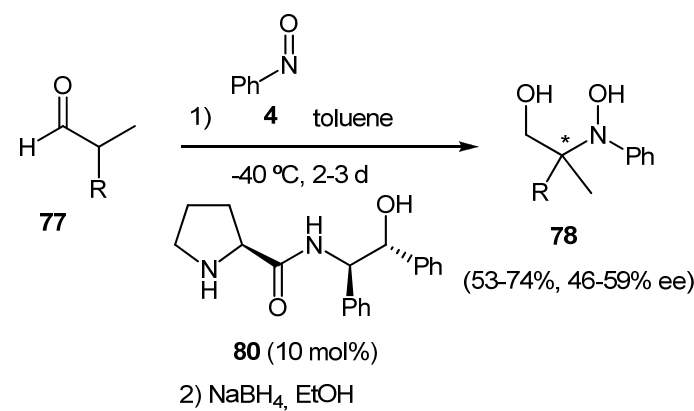

$\mathrm{R}=\mathrm{Et},{ }^{n} \mathrm{Pr},{ }^{-}-^{t} \mathrm{BuC}_{6} \mathrm{H}_{4} \mathrm{CH}_{2}, 4^{-}{ }^{-} \mathrm{PrC}_{6} \mathrm{H}_{4} \mathrm{CH}_{2}$,<smiles>C[C](Cc1ccc2c(c1)OCO2)CC(C)COCO</smiles>

Scheme 19

Pyrrolidine sulfonamide $\mathbf{8 1}$ exhibited high enantioselectivities ( $>99 \%$ ee in all cases) in a variety of organic solvents including, $\mathrm{DMSO}, \mathrm{CHCl}_{3}, \mathrm{DMF}, \mathrm{THF}, \mathrm{EtOAc}$ and $\mathrm{MeCN}$. The best results in terms of chemical yield were observed with DMSO which was selected for studying the scope of the reaction (Table 12). ${ }^{65}$ One year later, Córdova and co-workers reported the use of pyrroldine sulfonamide $\mathbf{8 2}$ also in DMSO as a solvent (Table 11). ${ }^{66}$ Catalyst 82 was also used for tandem O-nitroso aldol / Michael reaction previously reported by Yamamoto, ${ }^{59}$ but lower yields (22-23\%) than those described were obtained.<smiles>O=S(=O)(NCC1CCCN1)C(F)(F)F</smiles>

81

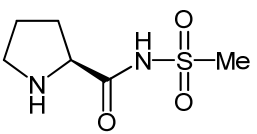

82

Figure 4. Pyrrolidine-sulfonamides

Table 12 a-Aminoxylation reaction of aldehydes and ketones catalyzed by pyrrolidine-sulfonamidesa

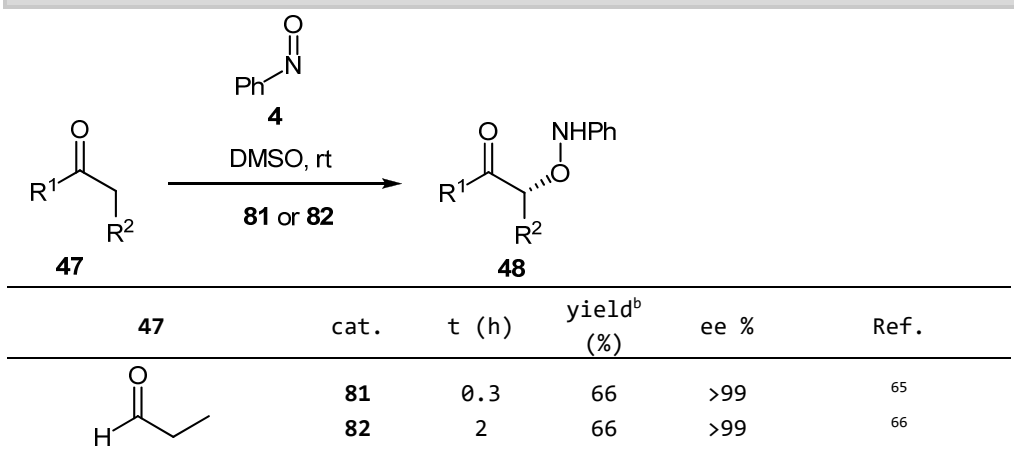




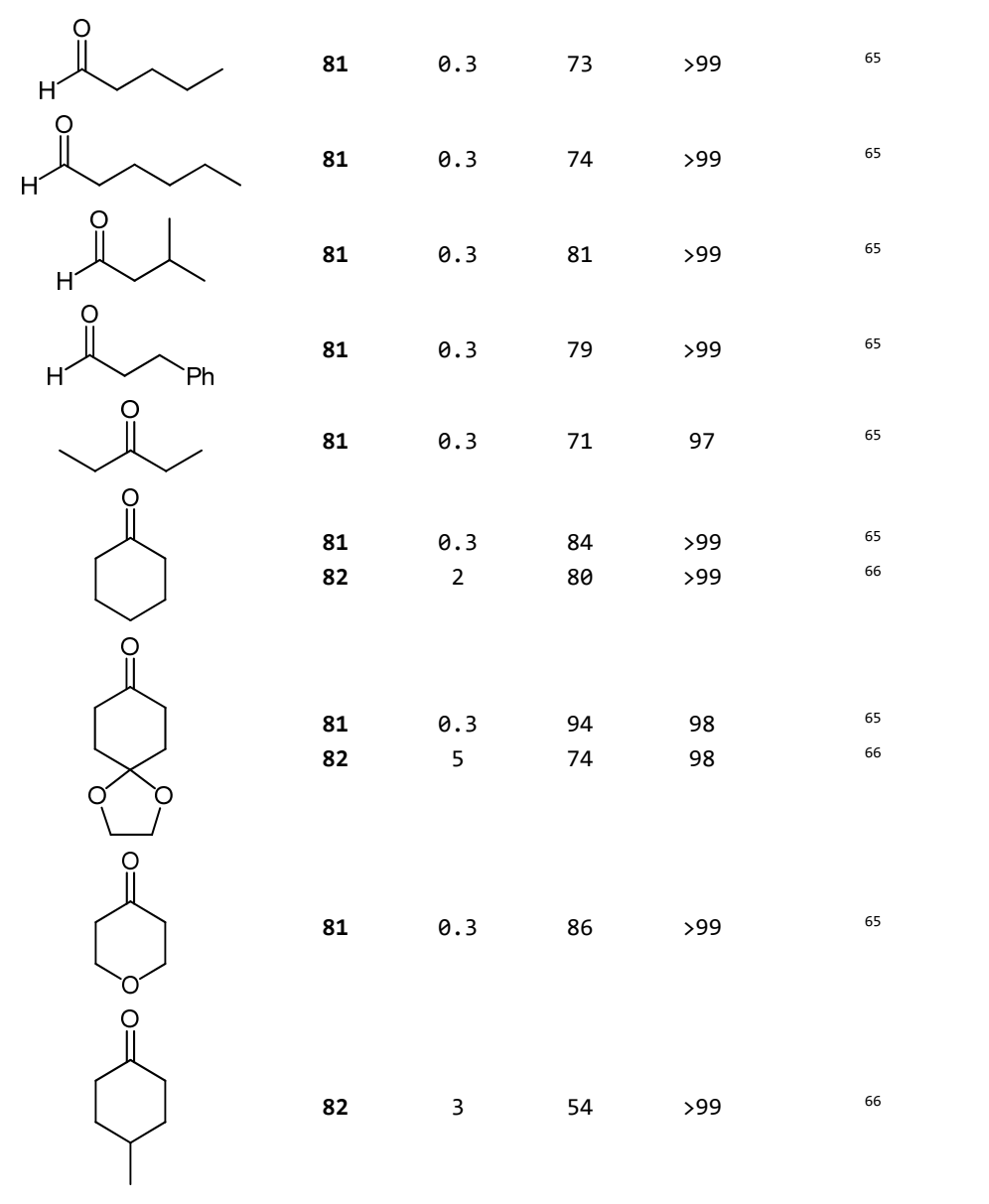

a Reactions with catalyst 81 (20 mol\%) were conducted with 2 equiv of nitrosobenzene and 1 equiv of aldehyde or ketone; reactions with catalyst 82 (10 mol\%) were conducted with 1 equiv of nitrosobenzene and 2 equiv of aldehyde or ketone.

Maruoka and co-workers reported ${ }^{67}$ the use of binaphthyl-derived secondary amine 83a (Figure 5) as a suitable organocatalyst for nitroso aldol reactions. The reaction was completely $N$-selective and hydroxyaminated adducts 87 were obtained in high yields and enantioselectivities (Table12). On the other hand, aminoacid 84 and aminosulfonamide 85 promoted $O$-selective reactions. ${ }^{68}$ Moreover, complementary induction of enantioselectivity was achieved with both $\mathbf{8 5}$ and $\mathbf{8 6}$, which led to $R$ and $S$ diols 88, respectively (Table 13). Higher enantiomeric excesses were observed for $\mathbf{8 8}$ which showed to be extremely efficient since it could be used at $0.2 \mathrm{~mol} \%$, the reaction going to completion in 8 hours with the same enantioselectivity. Those organocatalysts represent the first example of $O$-nitroso aldol reactions with a non-pyrrolidine derived organocatalyst. Interestingly, the same sense of enantioselectivity was observed for both catalysts with cyclohexanone. Whereas 85 led to the $R$ enantiomer $(63 \%, 99 \%$ ee), catalyst 86 furnished the $S$ enantiomer although with lower enantioselectivity (71\%, $74 \%$ ee) 


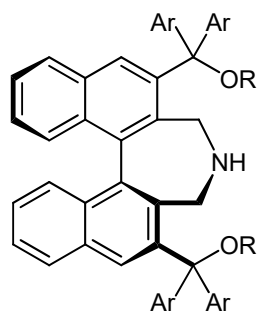

$83 \mathrm{R}=\mathrm{H} \quad \mathrm{Ar}=\mathrm{Ph}$

$84 \mathrm{R}=\mathrm{TES} \quad \mathrm{Ar}=3,5-\mathrm{F}_{2} \mathrm{C}_{6} \mathrm{H}_{5}$<smiles></smiles><smiles>CCCNc1cc2ccccc2c2c1CNCc1ccc3ccccc3c1-2</smiles>

Figure 5. Binaphthyl-derived organocatalysts

Table 13 Complementary a-Aminoxylation reaction of aldehydes catalyzed by binaphthyl-derived catalysts ${ }^{a}$

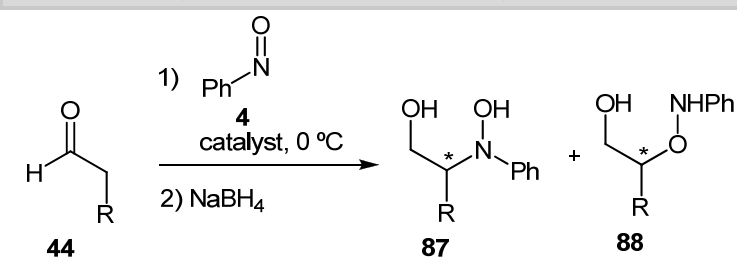

\begin{tabular}{|c|c|c|c|c|c|c|}
\hline $\mathrm{R}$ & cat. ${ }^{b}$ & $\begin{array}{c}t \\
(h)\end{array}$ & $\begin{array}{c}\text { yield } \\
(\%)\end{array}$ & product & ee $\%$ & Ref. \\
\hline \multirow[t]{3}{*}{ Me } & 83 & 1 & 90 & 87 & $99(S)$ & 67 \\
\hline & 85 & 1 & 89 & 88 & $86(R)$ & 68 \\
\hline & 86 & 2 & 86 & 88 & $98(S)$ & 68 \\
\hline Et & 86 & 2 & 90 & 88 & $97(S)$ & 68 \\
\hline \multirow[t]{3}{*}{${ }^{n} \mathrm{Bu}$} & 83 & 1 & 76 & 87 & $96(S)$ & 67 \\
\hline & 85 & 2 & 81 & 88 & $88(R)$ & 68 \\
\hline & 86 & 2 & 92 & 88 & $98(S)$ & 68 \\
\hline \multirow[t]{3}{*}{ benzyl } & 83 & 1 & 80 & 87 & $98(S)$ & 67 \\
\hline & 85 & 3 & 75 & 88 & $59(R)$ & 68 \\
\hline & 86 & 2 & 88 & 88 & $97(S)$ & 68 \\
\hline \multirow[t]{6}{*}{${ }^{i} \mathrm{Pr}$} & 83 & 1 & 70 & 87 & $97(S)$ & 67 \\
\hline & 85 & 1.5 & 69 & 88 & $86(R)$ & 68 \\
\hline & 86 & 2 & 96 & 88 & $98(S)$ & 68 \\
\hline & $86^{c}$ & 3 & 77 & 88 & $98(S)$ & 68 \\
\hline & $86^{d}$ & 8 & 70 & 88 & $98(S)$ & 68 \\
\hline & $86^{d}$ & 8 & 49 & 88 & $98(S)$ & 68 \\
\hline allyl & 86 & 2 & 92 & 88 & $97(S)$ & 68 \\
\hline $\mathrm{BnOCH}_{2}$ & 86 & 2 & 92 & 88 & $97(S)$ & 68 \\
\hline $\mathrm{CH}_{2}=\mathrm{CH}\left(\mathrm{CH}_{2}\right)_{7}$ & 83 & 1 & 77 & 87 & $99(S)$ & 67 \\
\hline${ }^{c} \mathrm{C}_{6} \mathrm{H}_{11} \mathrm{CH}_{2}$ & 83 & 1 & 86 & 87 & $99(S)$ & 67 \\
\hline $\mathrm{BnO}\left(\mathrm{CH}_{2}\right)_{3}$ & 83 & 1 & 86 & 87 & $97(S)$ & 67 \\
\hline
\end{tabular}

a Reactions were conducted with 1 equiv of nitrosobenzene and 3 equiv of aldehyde. b Reactions catalyzed by 83 were carried out in THF using $10 \mathrm{~mol} \%$ of catalyst and reactions catalyzed by 85 or 86 were carried out in $\mathrm{CHCl}_{3}$ using 5 mol\% of catalyst. ' 1 mol\% of catalyst was used. d 0.5 mol\% of catalyst was used. e 0.2 mol\% of catalyst was used. 
From a mechanistic point of view, it was suggested that the each of hydroxydiphenylmethyl groups on $\mathbf{8 3}$ might play a different role. ${ }^{67}$ Whereas one of them shields the $R e$ face of the enamine, the other one directs and activates the $N$ addition through a H-bond with the oxygen atom of the nitroso compounds (Figure 6). By using catalysts 85 and $\mathbf{8 6}$ bearing more acidic groups, protonation of the nitrogen atom of the nitroso group should be favored thus promoting $O$-selective reactions. ${ }^{68}$ Different transition states were suggested for the mode action of 85 and 86 (Figure 6). With compound $\mathbf{8 5}$ nitrosobenzene is activated and directed by the carboxyl group thus approaching the $R e$ face of the $s$-trans enamine to give the $R$ isomer. On the other hand, with compound $\mathbf{8 6}$ nitrosobenzene is activated by the distal acidic proton of the triflamide, approaching by the $S i$ face of the s-cis-enamine, leading to $S$ isomer.

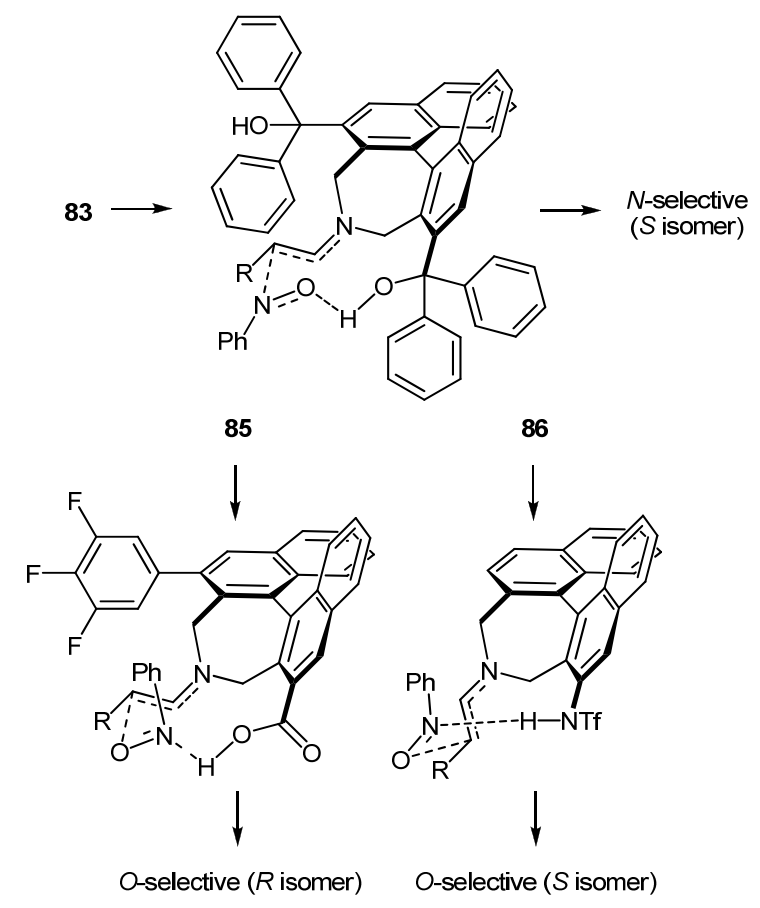

Figure 6. Transition states for catalysts 83,85 and 86

O-Silylated binhaphthyl derivative $\mathbf{8 4}$ catalyzed the addition of nitrosoformates to aldehydes (Scheme 20). ${ }^{69}$ Complete $N$-selectivity was observed and the reaction proceeded with good yields and very high enantioselectivity. The oxidation in situ of the protected hydroxylamines $\mathbf{1 3}$ and $\mathbf{1 7}$, precursors of nitrosoformates, was carried out with a mixture of benzoyl peroxide (BPO) and TEMPO. The same reaction was catalyzed by commercially available $\mathbf{8 9} .{ }^{70}$ Also in this case complete $N$-selectivity and enantioselectivity (99\% ee) was achieved. 


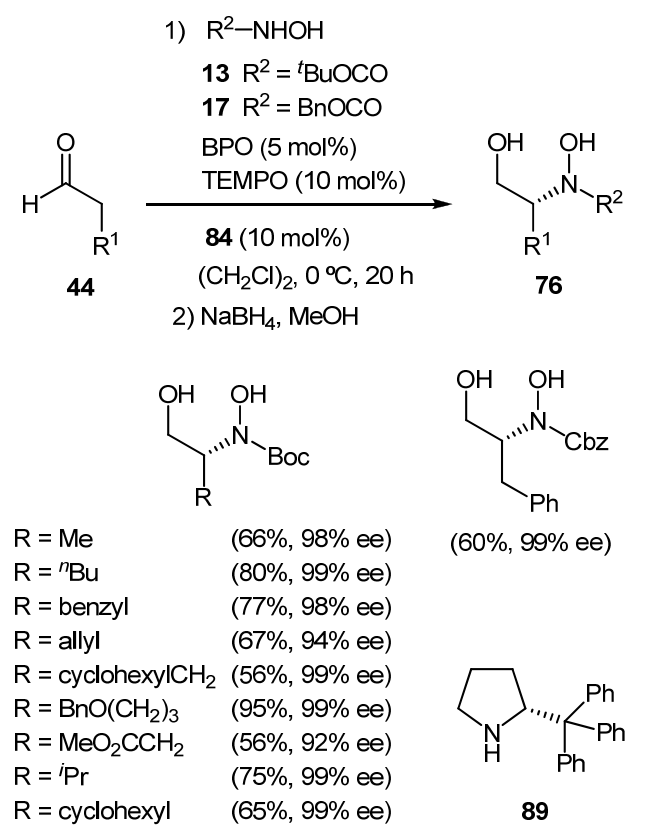

\section{Scheme 20}

Palomo and co-workers reported ${ }^{71}$ that using commercially available 64 the nitroso aldol reaction with aldehydes could be completely regiocontrolled by the solely addition of an external Brønsted acid capable of protonating the nitrogen atom of the nitrosobenzene. The reaction of nitrosobenzene 4 with aldehydes 44 provided the corresponding $N$-adducts $\mathbf{9 0}$ in total regioselectivity and very high yields and enantioselectivities (Table 14). DFT calculations suggested that the reaction proceeds via an enol intermediate and not via an enamine intermediate. ${ }^{72}$ On the other hand, when the reaction was carried out in the presence of $10 \mathrm{~mol} \%$ of $p$-nitrobenzoic acid the corresponding $O$-adducts 91 were the only products obtained in the reaction. ${ }^{73}$ In this case the enantioselective induction (giving rise to $S$ enantiomers) was opposite to that observed for L-proline (promoting the formation of $R$ enantiomers) and other pyrrolidine derivatives capable of promoting hydrogen transfer. In the case of compound 64 a classical steric model operates for the $O$-selective reaction and the attack of the nitroso compound takes place from the opposite face to the bulky group $\mathrm{C}\left(\mathrm{Ph}_{2}\right) \mathrm{OTMS}$. 
Table 14 Regiocontrolled nitroso aldol reaction of aldehydes ${ }^{a}$

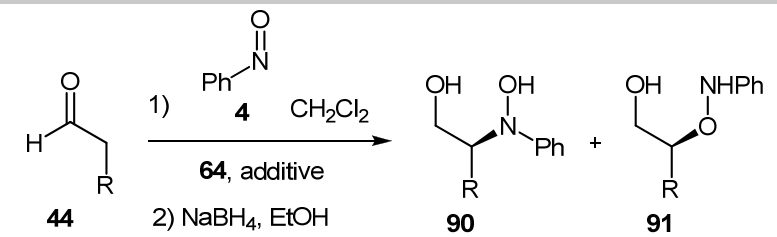

\begin{tabular}{|c|c|c|c|c|c|c|c|c|}
\hline $\mathrm{R}$ & $\begin{array}{c}\text { Cat } \\
\text { mol\% }\end{array}$ & additive $^{b}$ & $\mathrm{t}$ & $\begin{array}{c}\mathrm{T} \\
(\stackrel{\circ}{ }) \\
\end{array}$ & $\begin{array}{c}\text { yield } \\
(\%)\end{array}$ & $90: 91$ & ee $\%$ & Ref. \\
\hline Me & 20 & none & $5 \mathrm{~min}$ & rt & 70 & $>99: 1$ & 94 & 71 \\
\hline Et & 20 & none & $5 \mathrm{~min}$ & $r t$ & 65 & $>99: 1$ & 99 & 71 \\
\hline \multirow[t]{4}{*}{${ }^{n} \mathrm{Pr}$} & 20 & none & $10 \mathrm{~min}$ & 0 & 60 & $>99: 1$ & 96 & 71 \\
\hline & 20 & none & $30 \mathrm{~min}$ & -20 & 66 & $>99: 1$ & 98 & 71 \\
\hline & 10 & $p-\mathrm{NO}_{2} \mathrm{CO}_{2} \mathrm{H}$ & $2 \mathrm{~h}$ & -20 & 78 & $0: 1$ & $>99$ & 73 \\
\hline & 5 & $p-\mathrm{NO}_{2} \mathrm{CO}_{2} \mathrm{H}$ & $16 \mathrm{~h}$ & -20 & 71 & $0: 1$ & $>99$ & 73 \\
\hline${ }^{n} \mathrm{C}_{5} \mathrm{H}_{11}$ & 20 & none & $16 \mathrm{~h}$ & -20 & $74^{c}$ & $>99: 1$ & 98 & 71 \\
\hline \multirow[t]{2}{*}{${ }^{n} \mathrm{C}_{6} \mathrm{H}_{13}$} & 20 & none & $16 \mathrm{~h}$ & -20 & $75^{c}$ & $>99: 1$ & 98 & 71 \\
\hline & 20 & none & $5 \mathrm{~min}$ & $r t$ & 42 & $>99: 1$ & n.d. & 71 \\
\hline${ }^{n} \mathrm{Bu}$ & 10 & $p-\mathrm{NO}_{2} \mathrm{CO}_{2} \mathrm{H}$ & $2 \mathrm{~h}$ & -20 & 81 & $0: 1$ & $>99$ & 73 \\
\hline \multirow[t]{3}{*}{ benzyl } & 20 & none & $5 \mathrm{~min}$ & 0 & 70 & $>99: 1$ & 94 & 71 \\
\hline & 10 & $p-\mathrm{NO}_{2} \mathrm{CO}_{2} \mathrm{H}$ & $5 \mathrm{~h}$ & -20 & 68 & $0: 1$ & $>99$ & 73 \\
\hline & 5 & $p-\mathrm{NO}_{2} \mathrm{CO}_{2} \mathrm{H}$ & $16 \mathrm{~h}$ & -20 & 68 & $0: 1$ & $>99$ & 73 \\
\hline \multirow[t]{3}{*}{${ }^{i} \mathrm{Pr}$} & 20 & none & $30 \mathrm{~min}$ & 0 & 60 & $>99: 1$ & 99 & 71 \\
\hline & 10 & $p-\mathrm{NO}_{2} \mathrm{CO}_{2} \mathrm{H}$ & $2 \mathrm{~h}$ & -20 & 55 & $0: 1$ & $>99$ & 73 \\
\hline & 20 & $p-\mathrm{NO}_{2} \mathrm{CO}_{2} \mathrm{H}$ & $3 \mathrm{~h}$ & -20 & 59 & $0: 1$ & $>99$ & 73 \\
\hline $\mathrm{BnOCH}_{2}$ & 10 & $p-\mathrm{NO}_{2} \mathrm{CO}_{2} \mathrm{H}$ & $16 \mathrm{~h}$ & -20 & 45 & $0: 1$ & $>99$ & 73 \\
\hline $\operatorname{BocHN}\left(\mathrm{CH}_{2}\right)_{4}$ & 10 & $p-\mathrm{NO}_{2} \mathrm{CO}_{2} \mathrm{H}$ & $3 \mathrm{~h}$ & -20 & 88 & $0: 1$ & $>99$ & 73 \\
\hline $\mathrm{CH}_{2}=\mathrm{CH}\left(\mathrm{CH}_{3}\right)_{2}$ & 10 & $p-\mathrm{NO}_{2} \mathrm{CO}_{2} \mathrm{H}$ & $4 \mathrm{~h}$ & -20 & 66 & $0: 1$ & $>99$ & 73 \\
\hline $2-\mathrm{MeOC}_{6} \mathrm{H}_{4} \mathrm{CH}_{2}$ & 20 & none & $5 \mathrm{~min}$ & $\theta$ & 40 & $>99: 1$ & 91 & 71 \\
\hline
\end{tabular}

a Reactions were conducted with 1 equiv of nitrosobenzene and 3 equiv of aldehyde. ${ }^{b} p$-nitrobenzoic acid was used in $10 \mathrm{~mol} \%$. ' reaction carried out in THF as a solvent

According to DFT calculations ${ }^{73}$ the ultimate reason for the different regioselectivity observed in the presence of a Brønsted acid is a considerable lower energy barrier in the case of protonated nitrosobenzene (from $21.4 \mathrm{kcal} / \mathrm{mol}$ in the absence of any additive to $1.3 \mathrm{kcal} / \mathrm{mol}$ in the presence of $p$-nitrobenzoic acid).

Zhong and co-workers reported ${ }^{74}$ the first chiral phosphoric acid-catalyzed $\alpha$ hydroxylation of $\beta$-dicarbonyl compounds 92 through a tandem $\alpha$-aminoxylation/ $\mathrm{N}-\mathrm{O}$ bond heterolysis sequence (Scheme 21). The reaction was carried out with 4chloronitrosobenzene which showed better enantiocontrol than nitrosobenzene. Catalyst 94 could be used as low as $0.5 \mathrm{~mol} \%$ without decrease in ee or $\mathrm{O} / \mathrm{N}$ selectivity although for practical reasons it was preferred to be used in $1 \mathrm{~mol} \%$. 


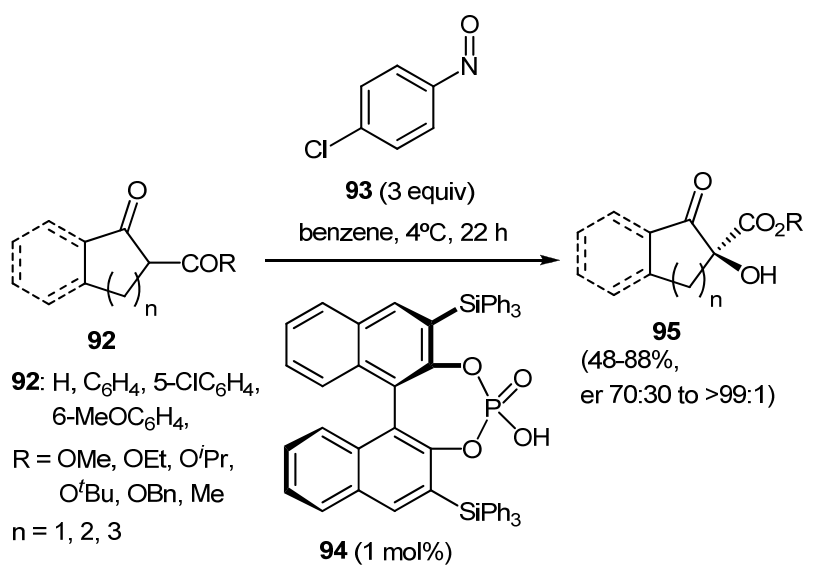

\section{Scheme 21}

Dimeric quinidine 96 (Figure 7) catalyzed enantioselective $\alpha$-aminoxylation of oxindoles 34 to give 3-hydroxyindole derivatives 100 (Scheme 20). The reaction furnished quaternary centers at the $\mathrm{C} 3$ position of oxindoles in good yields and ee's. ${ }^{75}$ On the other hand, cinchona-derived catalyst 97 showed exclusive $\mathrm{N}$-selectivity furnishing the corresponding $N$-adducts $\mathbf{1 0 1}$ in good yields although moderate enantioselectivity. ${ }^{76}$ The stereoselective induction of the electrophilic attack of the nitroso moiety was opposite by using catalysts 96 and 97.<smiles></smiles><smiles>[R]C1CCCCC1NC(=S)Nc1cc(C(F)(F)F)cc(C(F)(F)F)c1</smiles>

Figure 7. Organocatalysts used in nitroso aldol reactions of oxindoles 


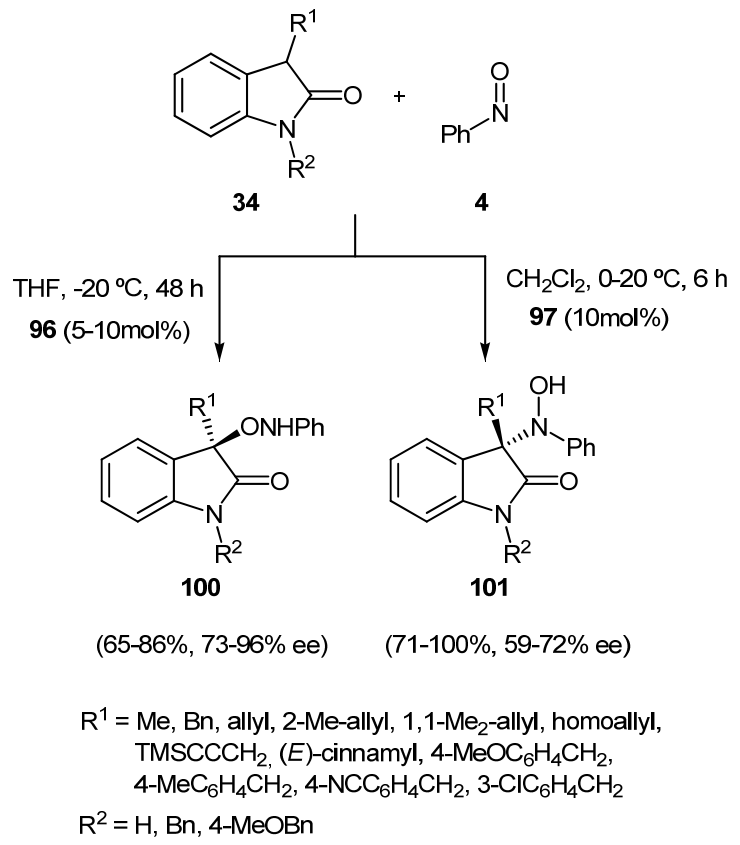

\section{Scheme 22}

Wang ${ }^{77}$ and Moyano ${ }^{78}$ simultaneously reported the asymmetric hydroxyamination of oxindoles catalyzed by bifunctional tertiary amine thioureas 98 and 99 , respectively. The same enantioselective induction was observed for both catalysts (contrary to that observed with 97), compound 98 providing better results under standard isolation of the corresponding product. However, in the case of catalyst 99 gradual precipitation of the product was observed. ${ }^{78}$ After collection of this solid by simple filtration when the reaction was complete it was observed that in all instances the enantiomeric purity of the precipitated product was much higher (up to $99 \%$ ee) than that resulting from the work up of the complete reaction crude (Scheme 23).

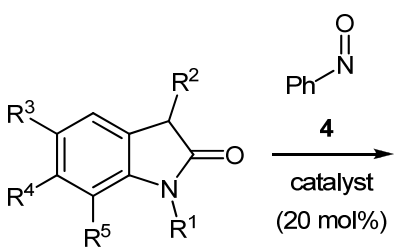

34

$$
\begin{aligned}
& \text { catalyst 98: toluene, } 25^{\circ} \mathrm{C}, 1.5-11 \mathrm{~h} \quad(51-91 \%, 76-90 \% \text { ee }) \\
& \text { catalyst 99: }{ }^{t} \mathrm{BuOMe}, \mathrm{rt}, 14-24 \mathrm{~h} \quad(68-96 \%, 37-70 \% \text { ee) } \\
& \mathrm{R}^{1}=\mathrm{H}, \mathrm{Me}, \mathrm{Et},{ }^{i} \mathrm{Pr} \text {, }{ }^{i} \mathrm{iBu}, \mathrm{Ph}\left(\mathrm{CH}_{2}\right)_{3}, \mathrm{Bn}, 4-\mathrm{BrC}_{6} \mathrm{H}_{4} \mathrm{CH}_{2} \text {, } \\
& 2,6-\mathrm{Cl}_{2} \mathrm{C}_{6} \mathrm{H}_{3} \mathrm{CH}_{2} \\
& \mathrm{R}^{2}=\mathrm{Bn}, 4-\mathrm{ClC}_{6} \mathrm{H}_{4} \mathrm{CH}_{2}, 3-\mathrm{MeC}_{6} \mathrm{H}_{4} \mathrm{CH}_{2}, 4-\mathrm{FC}_{6} \mathrm{H}_{4} \mathrm{CH}_{2} \text {, } \\
& \text { 4- } \mathrm{BrC}_{6} \mathrm{H}_{4} \mathrm{CH}_{2}, 4-\mathrm{MeOC}_{6} \mathrm{H}_{4} \mathrm{CH}_{2}, 3-\mathrm{ClC}_{6} \mathrm{H}_{4} \mathrm{CH}_{2} \text {, } \\
& \mathrm{R}^{3}=\mathrm{H}, \mathrm{Br} \quad \mathrm{R}^{3}=\mathrm{H}, \mathrm{Cl} \quad \mathrm{R}^{5}=\mathrm{H}, \mathrm{F}
\end{aligned}
$$

\section{Scheme 23}


Takemoto's thiourea 99 also catalyzed the $\alpha$-hydroxyamination of $\beta$-ketoamides 103.

The reactions required a low catalyst loading $(0.5 \mathrm{~mol} \%)$ for obtaining high enantioselectivities (Scheme 24). ${ }^{79}$
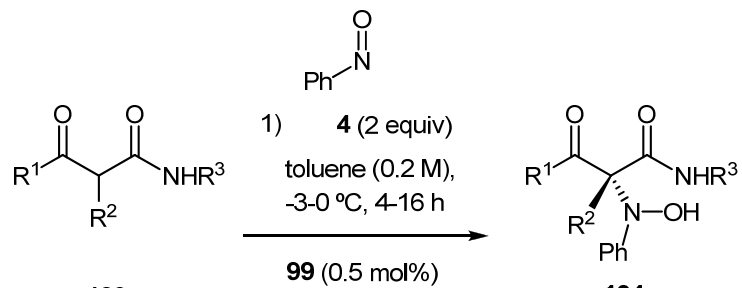

103
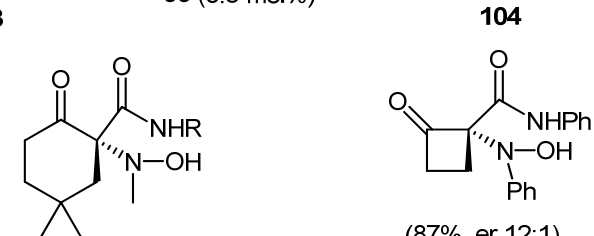

$$
\begin{aligned}
& \mathrm{R}=\mathrm{Ph} \\
& \text { (88\%, er >200:1) } \\
& \mathrm{R}=4-\mathrm{MeC}_{6} \mathrm{H}_{5} \\
& \mathrm{R}=2{ }^{\mathrm{i}} \mathrm{PrC}_{6} \mathrm{H}_{5} \\
& \mathrm{R}=4-\mathrm{BrC}_{6} \mathrm{H}_{5} \\
& \text { (98\%, er } 15: 1) \\
& \text { (45\%, er >200:1) } \\
& \text { (96\%, er 12:1) } \\
& \text { (96\%, er 4.3:1) } \\
& \text { (91\%, er 3.5:1) } \\
& \text { (89\%, er 3.6:1) } \\
& \mathrm{R}={ }^{t} \mathrm{Bu} \\
& \text { (84\%, er 191:1) } \\
& \mathrm{R}=4-\mathrm{FC}_{6} \mathrm{H}_{5} \\
& \text { (66\%, er 155:1) }
\end{aligned}
$$

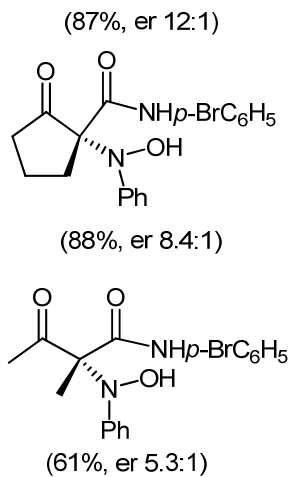

\section{Scheme 24}

Jørgensen and co-workers reported ${ }^{80}$ the enantioselective nitroso aldol reaction between $\alpha$-aryl-acyanoacetates 105 and nitrosobenzene 4 catalyzed by quinine 106 . The in situ reduction with $\mathrm{Zn}$ in acetic acid afforded the corresponding $\alpha$-aminonitriles 107 in high yield and moderate enantioselectivity (Scheme 24). An unusual effect on the enantioselectivity depending on both solvent and catalyst loading was observed. 


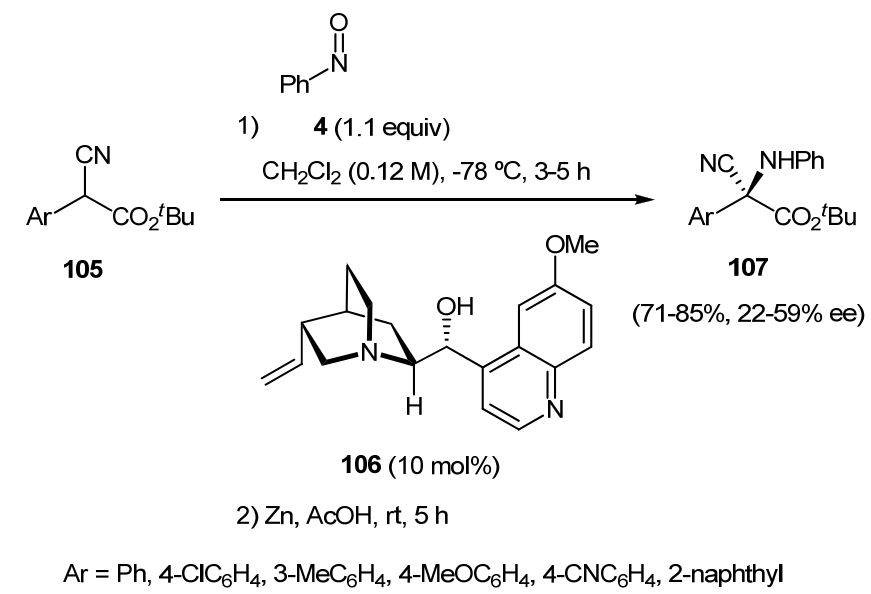

\section{Scheme 25}

Cinchona squaramide bifunctional catalyst $\mathbf{1 0 9}$ catalyzed the nitroso aldol reaction between tertiary $\beta$-carbonyl esters $\mathbf{1 0 8}$ and nitrosobenzene. ${ }^{81}$ The reaction proceeded rapidly in the presence of $5 \mathrm{~mol} \%$ of catalyst to furnish compounds $\mathbf{1 1 0}$, bearing a quaternary center, in moderate to good enantioselectivities (Scheme 25).
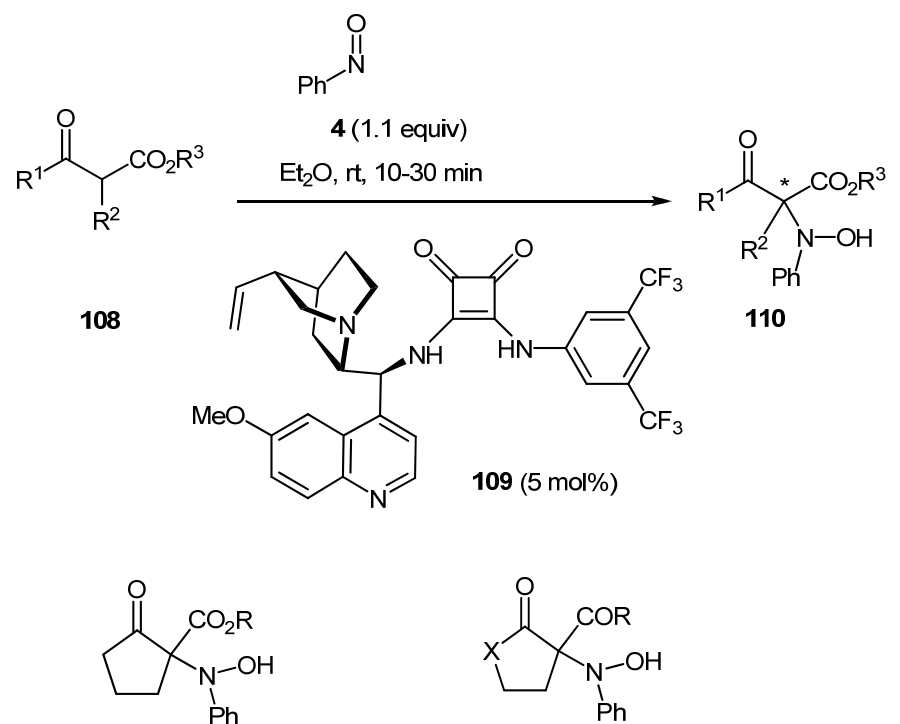

$$
\begin{array}{ll}
\mathrm{R}=\mathrm{Me} & (48 \%, 96 \% \text { ee }) \\
\mathrm{R}=\mathrm{Et} & (43 \%, 98 \% \text { ee }) \\
\mathrm{R}=t_{\mathrm{Bu}} & (46 \%, 77 \% \text { ee) } \\
\mathrm{R}=\mathrm{Bn} \quad(40 \%, 94 \% \text { ee })
\end{array}
$$

$\mathrm{R}=\mathrm{Me} \quad \mathrm{X}=\mathrm{O} \quad(45 \%, 49 \%$ ee $)$

$(56 \%, 45 \%$ ee)

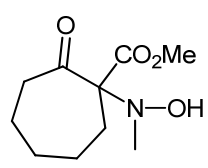

$(62 \%, 45 \%$ ee $)$

\section{Scheme 26}




\section{Enamine metal-free reactions}

The nitroso aldol reaction catalyzed by a secondary amine is, actually, the reaction between an enamine and the nitroso compound in the rate-limiting step. Thus, it is possible to react directly an enamine with the nitroso derivative. If the reaction is made in the presence of a chiral catalyst the process becomes enantioselective. In 2005 Yamamoto reported ${ }^{82}$ a totally regiocontrolled reaction between cyclic enamines and nitrosobenzene. Whereas the reaction catalyzed by glycocolic acid 111 (Figure 8) afforded $O$-nitroso aldol adducts 115 , by using TADDOL 112 as a catalyst, $N$-nitroso aldol products 116 were obtained (Table 15). With diol 113 complete $N$-selectivity was also observed. ${ }^{83}$<smiles>O=C(O)C(O)c1cccc2ccccc12</smiles>

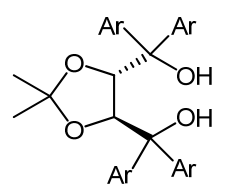
$112 \mathrm{Ar}=1$-naphthyll<smiles>CS(=O)(=O)c1cc2ccccc2c(-c2c(O)c(S(C)(=O)=O)cc3ccccc23)c1O</smiles>
$113 \mathrm{Ar}=3,5-\mathrm{xylyl}$

Figure 8. Catalysts for the reaction between enamines and nitroso compounds

The reaction outlined in Table 15 has been studied theoretically to rationalize the effect of the catalyst on the regio- and enantioselectivity ${ }^{84}$ Whereas the enantioselectivity is exclusively due to steric factors, three key H-bond interactions must be considered for rationalizing the regioselectivity. These $\mathrm{H}$-bonds are between the organic acid and i) the $-\mathrm{N}=\mathrm{O}$ group, ii) the ortho hydrogen atom in $\mathrm{PhNO}$ and iii) the hydrogen atom of the NMe part of the enamine. A comparison between the strengths of the $\mathrm{H}$-bonds and the energy levels of the transition structures allowed understanding the factors accounting for regioselectivity. 


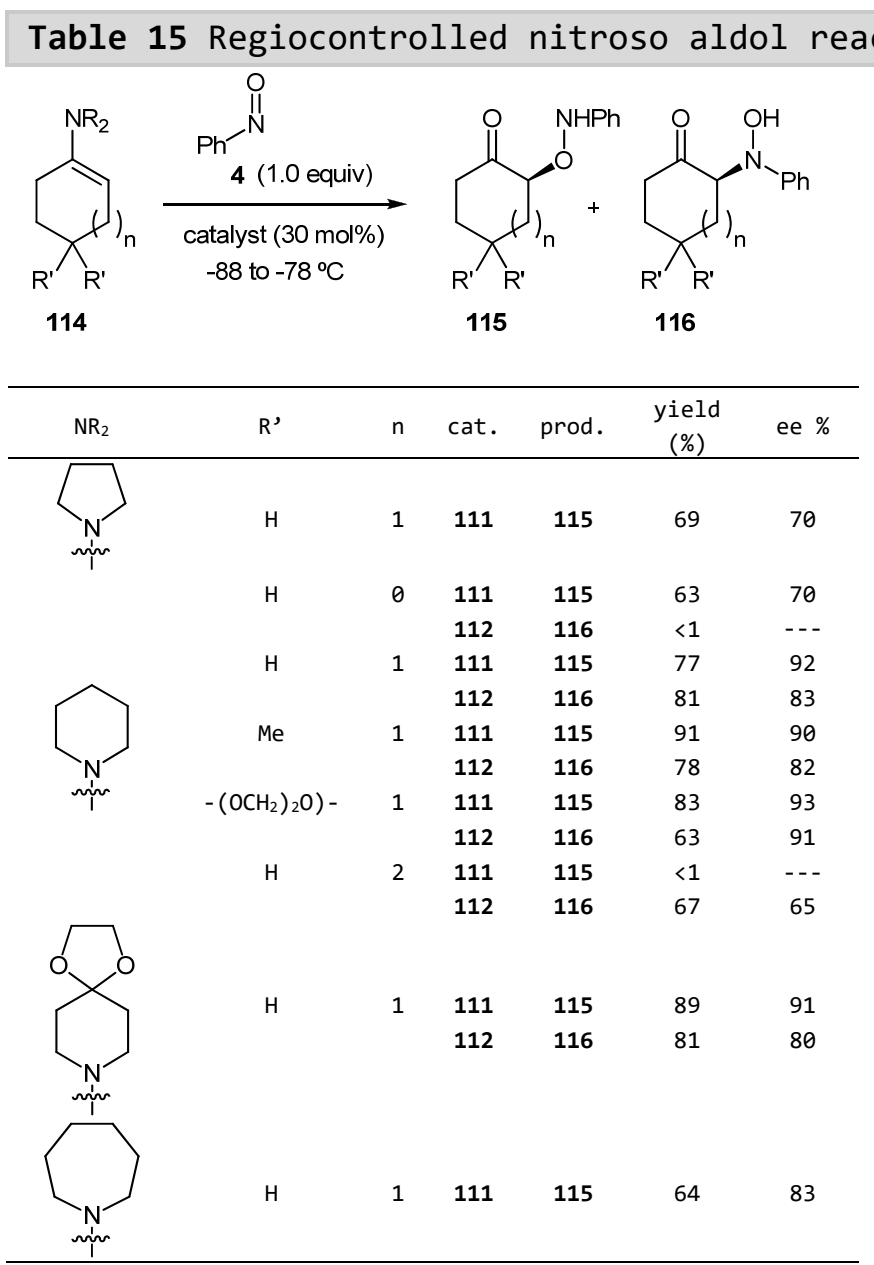

a Reactions with catalyst 111 were carried out in diethyl ether for $12 \mathrm{~h}$; reactions with catalyst 112 were carried out in toluene for $2 \mathrm{~h}$

The enantioselective $\alpha$-aminoxylation of enecarbamates 117, an activated ketone nucleophile, was reported by Zhong and co-workers. ${ }^{85}$ The presence of an electronwithdrawing carbamate group, instead of an electron-donating pyrrolidine moiety (in a typical enamine), avoid $N$-addition and only $O$-nitroso aldol adducts were obtained. The use of a strong Brønsted acid such as chiral phosphoric acid 118 favored protonation of the nitrogen atom of the nitroso compound, also directing the reaction towards $O$ - 
adducts (Scheme 26). Indeed, DFT calculations demonstrated that the path involving protonation of the nitrogen atom was favored by $2.91 \mathrm{kcal} / \mathrm{mol}$ over the path involving protonation of the oxygen atom.
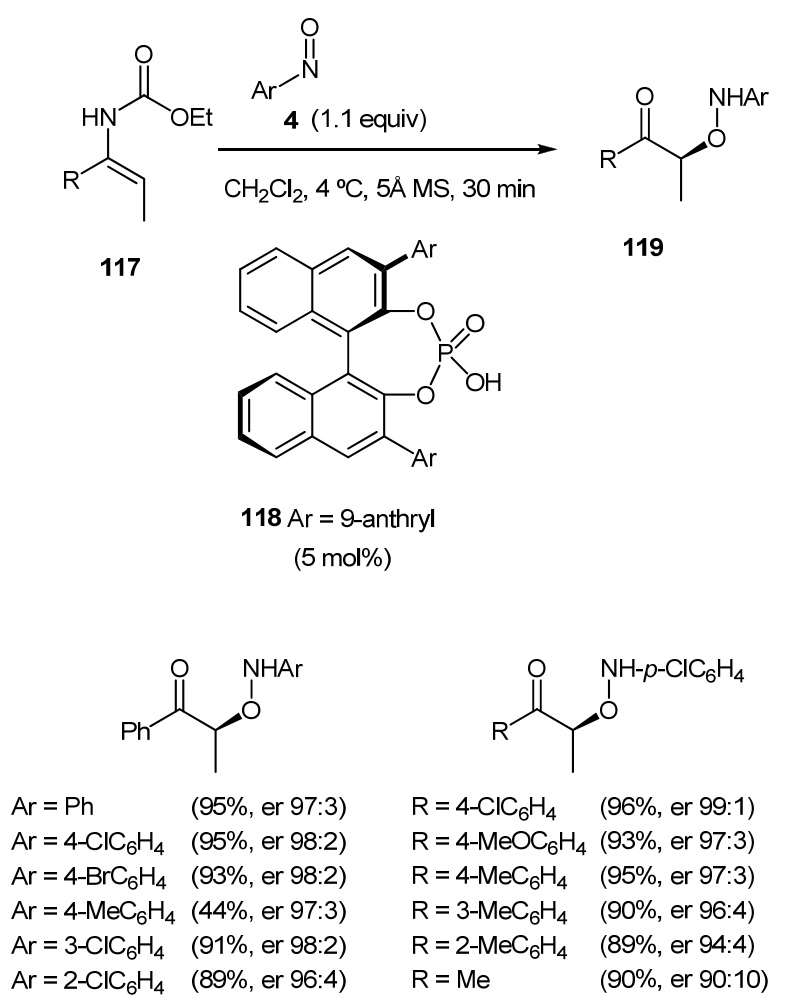

\section{Scheme 27}

The reaction showed a good scope with a broad spectrum of nitrosoarenes and it could be extended to enecarbamates derived from indanones and tetralones giving rise to $\alpha$ aminoxylated products in good yields (up to 91\%) and enantiomeric ratios (up to 96:4). The synthetic utility of the transformation was demonstrated by converting compounds 119 into the corresponding protected $\beta$-amino alcohols.

\section{Concluding Remarks}

The combined effort of several research groups throughout the world leadered by that of Prof. Hisashi Yamamoto in USA have made major contribution to the area of nitroso chemistry and in particular to catalytic asymmetric nitroso aldol reaction. Both metal and organic catalysts have proved to be effective for achieving a complete regioselectivity and high enantioselectivities thus rendering the nitroso aldol reaction in 
both $O$ - and $N$-selective paths synthetically very useful. The development of efficient catalysts has required a delicate balance between the sterics and electronics of the chiral control elements around the nitroso compound. For instance, preferential H-bond interaction of either the nitrogen atom or the oxygen atom of the $\mathrm{N}=\mathrm{O}$ group is crucial for the regioselectivity in organocatalytic reactions. In summary, several positive features for the catalytic asymmetric nitroso aldol reaction are worth of mention: i) The regioselectivity can be controlled completely using both metal and organic catalysis. ii) The substrate scope is broad including aldehydes, ketones, esters and amides. iii) Theoretically studied models allow rationalizing and predicting the regio- and stereochemical outcome of the reaction with a reasonable level of confidence. iv) Excellent levels of enantioselectivity are achieved with a variety of catalysts. v) The work-up of the reaction is easy and in many cases releasing of hydroxy and amino functionalities can be done in situ in a one-pot process. As a consequence, suitable methods for obtaining enantiomerically pure $\alpha$-amino and $\alpha$-hydroxy carbonyl compounds have been developed. Key challenges in this field lie in the further use of the nitroso aldol reaction in domino processes (only few examples are reported) and in the further optimization of the reactions already possible to other substrates including open-chain ketones and $\alpha$-branched aldehydes and ketones.

\section{Acknowledgments}

\section{References}

1. Zuman, P.; Shah, B. Chem. Rev. 1994, 94, 1621-1641.

2. Lee, J.; Chen, L.; West, A. H.; RichterAddo, G. B. Chem. Rev. 2002, 102, 1019-1065.

3. Yamamoto, H.; Kawasaki, M. Bull. Chem. Soc. Jpn. 2007, 80, 595-607.

4. Yamamoto, H.; Momiyama, N. Chem. Commun. (Cambridge, U. K.) 2005, 3514-3525.

5. $\quad$ Adam, W.; Krebs, O. Chem. Rev. 2003, 103, 4131-4146.

6. Baidya, M.; Yamamoto, H. Synthesis 2013, 45, 1931-1938.

7. Malkov, A. V. Chem. Heterocycl. Compd. 2012, 48, 39-43.

8. Yamamoto, Y.; Yamamoto, H. Eur. J. Org. Chem. 2006, 2031-2043.

9. Bodnar, B. S.; Miller, M. J. Angew. Chem., Int. Ed. 2011, 50, 5629-5646.

10. Leach, A. G.; Houk, K. N. J. Chem. Soc., Chem. Commun. 2002, 1243-1255.

11. Streith, J.; Defoin, A. Synthesis 1994, 1107-1117.

12. Sasaki, T.; Mori, K.; Ohno, M. Synthesis 1985, 279-280.

13. Momiyama, N.; Yamamoto, H. Angew. Chem. Int. Ed. 2002, 41, 2986-2988.

14. Morales, M. R.; Momiyama, N.; Yamamoto, H. Synlett 2006, 705-708.

15. Momiyama, N.; Yamamoto, H. Org. Lett. 2002, 4, 3579-3582. 
16. Merino, P.; Tejero, T. Angew. Chem., Int. Ed. 2004, 43, 2995-2997.

17. Yu, C.; Song, A.; Zhang, F.; Wang, W. ChemCatChem 2014, 6, 1863-1865.

18. Palmer, L. I.; Frazier, C. P.; Alaniz, J. R. d. Synthesis 2013, 269-280.

19. Momiyama, N.; Yamamoto, H. J. Am. Chem. Soc. 2003, 125, 6038-6039.

20. Kawasaki, M.; Li, P.; Yamamoto, H. Angew. Chem., Int. Ed. 2008, 47, 3795-3797.

21. Yanagisawa, A.; Takeshita, S.; Izumi, Y.; Yoshida, K. J. Am. Chem. Soc. 2010, 132, 5328-

5329.

22. Baidya, M.; Griffin, K. A.; Yamamoto, H. J. Am. Chem. Soc. 2012, 134, 18566-18569.

23. Frazier, C. P.; Sandoval, D.; Palmer, L. I.; Read de Alaniz, J. Chem. Sci. 2013, 4, 3857-

3862.

24. Sandoval, D.; Frazier, C. P.; Bugarin, A.; Read de Alaniz, J. J. Am. Chem. Soc. 2012, 134, 18948-18951.

25. Maji, B.; Yamamoto, H. Angew. Chem., Int. Ed. 2014, 53, 14472-14475.

26. Tian, G.-Q.; Yang, J.; Rosa-Perez, K. Org. Lett. 2010, 12, 5072-5074.

27. Momiyama, N.; Yamamoto, H. J. Am. Chem. Soc. 2004, 126, 5360-5361.

28. Yanagisawa, A.; Izumi, Y.; Takeshita, S. Synlett 2009, 716-719.

29. Yanagisawa, A.; Fujinami, T.; Oyokawa, Y.; Sugita, T.; Yoshida, K. Org. Lett. 2012, 14, 2434-2437.

30. Shen, K.; Liu, X.; Wang, G.; Lin, L.; Feng, X. Angew. Chem., Int. Ed. 2011, 50, 4684-4688, S4684/4681-S4684/4659.

31. Maji, B.; Baidya, M.; Yamamoto, H. Chem. Sci. 2014, 5, 3941-3945.

32. Selig, P. Angew. Chem., Int. Ed. 2013, 52, 7080-7082.

33. Xu, Y.-J.; Liu, Q.-Z.; Dong, L. Synlett 2007, 273-277.

34. Zhong, G. Angew. Chem. Int. Ed. 2003, 42, 4247-4250.

35. Brown, S. P.; Brochu, M. P.; Sinz, C. J.; MacMillan, D. W. C. J. Am. Chem. Soc. 2003, 125, 10808-10809.

36. Hayashi, Y.; Yamaguchi, J.; Hibino, K.; Shoji, M. Tetrahedron Lett. 2003, 44, 8293-8296.

37. Bogevig, A.; Sunden, H.; Cordova, A. Angew. Chem., Int. Ed. 2004, 43, 1109-1112.

38. Cordova, A.; Sunden, H.; Bogevig, A.; Johansson, M.; Himo, F. Chem. - Eur. J. 2004, 10, 3673-3684.

39. Hayashi, Y.; Yamaguchi, J.; Sumiya, T.; Shoji, M. Angew. Chem., Int. Ed. 2004, 43, 11121115.

40. Hayashi, Y.; Yamaguchi, J.; Sumiya, T.; Hibino, K.; Shoji, M. J. Org. Chem. 2004, 69, 5966-5973.

41. Hayashi, Y.; Yamaguchi, J.; Hibino, K.; Sumiya, T.; Urushima, T.; Shoji, M.; Hashizume, D.; Koshino, H. Adv. Synth. Catal. 2004, 346, 1435-1439.

42. Font, D.; Bastero, A.; Sayalero, S.; Jimeno, C.; Pericas, M. A. Org. Lett. 2007, 9, $1943-$ 1946.

43. An, Y.-J.; Wang, C.-C.; Xu, Y.-Z.; Wang, W.-J.; Tao, J.-C. Catal. Lett. 2011, 141, 11231129.

44. Cheong, P. H.-Y.; Houk, K. N. J. Am. Chem. Soc. 2004, 126, 13912-13913.

45. Ramachary, D. B.; Barbas, C. F., III Org. Lett. 2005, 7, 1577-1580.

46. Joseph, J.; Ramachary, D. B.; Jemmis, E. D. Org. Biomol. Chem. 2006, 4, 2685-2689.

47. Matsuzawa, M.; Kakeya, H.; Yamaguchi, J.; Shoji, M.; Onose, R.; Osada, H.; Hayashi, Y.

Chem. - Asian J. 2006, 1, 845-851.

48. $\quad$ Capitta, F.; Frongia, A.; Ollivier, J.; Piras, P. P.; Secci, F. Synlett 2011, 89-93.

49. Yang, L.; Liu, R.-H.; Wang, B.; Weng, L.-L.; Zheng, H. Tetrahedron Lett. 2009, 50, 2628-

2631.

50. Lin, H.; Tan, Y.; Sun, X.-W.; Lin, G.-Q. Org. Lett. 2012, 14, 3818-3821.

51. Guo, H.-M.; Niu, H.-Y.; Xue, M.-X.; Guo, Q.-X.; Cun, L.-F.; Mi, A.-Q.; Jiang, Y.-Z.; Wang, J.J. Green Chem. 2006, 8, 682-684.

52. Huang, K.; Huang, Z.-Z.; Li, X.-L. J. Org. Chem. 2006, 71, 8320-8323. 
53. Ding, X.; Tang, W.; Zhu, C.; Cheng, Y. Adv. Synth. Catal. 2010, 352, 108-112.

54. Khan, S. S.; Shah, J.; Liebscher, J. Tetrahedron 2011, 67, 1812-1820.

55. Poe, S. L.; Bogdan, A. R.; Mason, B. P.; Steinbacher, J. L.; Opalka, S. M.; McQuade, D. T. J. Org. Chem. 2009, 74, 1574-1580.

56. Demir, A. S.; Basceken, S. Tetrahedron Asymmetry 2013, 24, 1218-1224.

57. Momiyama, N.; Torii, H.; Saito, S.; Yamamoto, H. Proc. Natl. Acad. Sci. U. S. A. 2004, $101,5374-5378$.

58. Jiao, P.; Yamamoto, H. Synlett 2009, 2685-2687.

59. Yamamoto, Y.; Momiyama, N.; Yamamoto, H. J. Am. Chem. Soc. 2004, 126, 5962-5963.

60. Zhu, R.; Zhang, D.; Wu, J.; Liu, C. J. Mol. Struct. THEOCHEM 2007, 815, 105-109.

61. Jiao, P.; Kawasaki, M.; Yamamoto, H. Angew. Chem., Int. Ed. 2009, 48, 3333-3336, S3333/3331-S3333/3342.

62. Maji, B.; Yamamoto, H. Angew. Chem., Int. Ed. 2014, 53, 8714-8717.

63. Kim, S.-G.; Park, T.-H. Tetrahedron Lett. 2006, 47, 9067-9071.

64. Guo, H.-M.; Cheng, L.; Cun, L.-F.; Gong, L.-Z.; Mi, A.-Q.; Jiang, Y.-Z. Chem. Commun. (Cambridge, U. K.) 2006, 429-431.

65. Wang, W.; Wang, J.; Li, H.; Liao, L. Tetrahedron Lett. 2004, 45, 7235-7238.

66. Sunden, H.; Dahlin, N.; Ibrahem, I.; Adolfsson, H.; Cordova, A. Tetrahedron Lett. 2005, 46, 3385-3389.

67. Kano, T.; Ueda, M.; Takai, J.; Maruoka, K. J. Am. Chem. Soc. 2006, 128, 6046-6047.

68. Kano, T.; Yamamoto, A.; Shirozu, F.; Maruoka, K. Synthesis 2009, 1557-1563.

69. Kano, T.; Shirozu, F.; Maruoka, K. J. Am. Chem. Soc. 2013, 135, 18036-18039.

70. Kano, T.; Shirozu, F.; Maruoka, K. Org. Lett. 2014, 16, 1530-1532.

71. Palomo, C.; Vera, S.; Velilla, I.; Mielgo, A.; Gomez-Bengoa, E. Angew. Chem. Int. Ed. 2007, 46, 8054-8056.

72. Wong, C. T. Tetrahedron Lett. 2009, 50, 811-813.

73. Mielgo, A.; Velilla, I.; Gomez-Bengoa, E.; Palomo, C. Chem. - Eur. J. 2010, 16, 74967502, S7496/7491-S7496/7443.

74. Lu, M.; Zhu, D.; Lu, Y.; Zeng, X.; Tan, B.; Xu, Z.; Zhong, G. J. Am. Chem. Soc. 2009, 131, 4562-4563.

75. Bui, T.; Candeias, N. R.; Barbas, C. F. J. Am. Chem. Soc. 2010, 132, 5574-5575.

76. Zhang, T.; Cheng, L.; Liu, L.; Wang, D.; Chen, Y.-J. Tetrahedron Asymmetry 2010, 21, 2800-2806.

77. Jia, L.-N.; Huang, J.; Peng, L.; Wang, L.-L.; Bai, J.-F.; Tian, F.; He, G.-Y.; Xu, X.-Y.; Wang, L.-X. Org. Biomol. Chem. 2012, 10, 236-239.

78. Companyo, X.; Valero, G.; Pineda, O.; Calvet, T.; Font-Bardia, M.; Moyano, A.; Rios, R. Org. Biomol. Chem. 2012, 10, 431-439.

79. Mailhol, D.; Castillo, J.-C.; Mohanan, K.; Abonia, R.; Coquerel, Y.; Rodriguez, J.

ChemCatChem 2013, 5, 1192-1199.

80. Lopez-Cantarero, J.; Cid, M. B.; Poulsen, T. B.; Bella, M.; Garcia Ruano, J. L.; Jorgensen, K. A. J. Org. Chem. 2007, 72, 7062-7065.

81. Yang, H.-J.; Dai, L.; Yang, S.-Q.; Chen, F.-E. Synlett 2012, 23, 948-950.

82. Momiyama, N.; Yamamoto, H. J. Am. Chem. Soc. 2005, 127, 1080-1081.

83. Momiyama, N.; Yamamoto, Y.; Yamamoto, H. J. Am. Chem. Soc. 2007, 129, 1190-1195.

84. Akakura, M.; Kawasaki, M.; Yamamoto, H. Eur. J. Org. Chem. 2008, 4245-4249.

85. Lu, M.; Lu, Y.; Zhu, D.; Zeng, X.; Li, X.; Zhong, G. Angew. Chem., Int. Ed. 2010, 49, 85888592, S8588/8581-S8588/8570. 